\title{
Cenpj Regulates Cilia Disassembly and Neurogenesis in the Developing Mouse Cortex
}

\author{
Wenyu Ding, ${ }^{1,2 \star}$ Qian Wu, ${ }^{1,2 \star}$ Le Sun, ${ }^{1,2}$ Na Clara Pan, ${ }^{1,2}$ and Xiaoqun Wang ${ }^{1,2,3}$ \\ ${ }^{1}$ State Key Laboratory of Brain and Cognitive Science, Chinese Academy of Sciences Center for Excellence in Brain Science and Intelligence Technology \\ (Shanghai), Institute of Biophysics, Chinese Academy of Sciences, Beijing 100101, China, ${ }^{2}$ University of Chinese Academy of Sciences, Beijing 100049 , \\ China, and ${ }^{3}$ Beijing Institute for Brain Disorders, Beijing 100069, China
}

Primary cilia are microtubule-based protuberances that project from the eukaryotic cell body to sense the extracellular environment. Ciliogenesis is closely correlated to the cell cycle and defects of cilia are related to human systemic diseases such as primary ciliary dyskinesia. However, the role of ciliogenesis in cortical development remains unclear. Here, we demonstrate that Cenpj, a protein that is required for centriole biogenesis, plays a role in regulating cilium disassembly in vivo. Depletion of Cenpj in neural progenitor cells results in long cilia and abnormal cilia disassembly. Radial glial cells Cenpj depletion exhibit uncompleted cell division, reduced cell proliferation, and increased cell apoptosis in the developing mouse cerebrum cortex, leading to microcephaly. In addition, Cenpj depletion causes long and thin primary cilia and motile cilia in adult neural stem cells and reduced cell proliferation in the subventricular zone. Furthermore, we show that Cenpj regulates cilia disassembly and neurogenesis through Kif2a, a plus-end-directed motor protein. These data collected from mice of both sexes provide insights into how ciliogenesis plays roles in cortical development and how primary microcephaly is induced by Cenpj mutations in humans.

Key words: CenpJ; cerebral cortex; neurogenesis; primary cilia; radial glial cell; subventricular zone

\section{Significance Statement}

Autosomal recessive primary microcephaly is a neurodevelopmental disorder with the major symptoms of reduction of circumference of the head, brain volume, and cortex thickness with normal brain architecture in birth. We used conditional Cenpj deletion mice and found that neural progenitor cells (NPCs) exhibited long primary cilia and abnormal cilium appendages. The defective cilium disassembly caused by Cenpj depletion might correlate to reduced cell proliferation, uncompleted cell division, cell apoptosis, and microcephaly in mice. Cenpj also regulates the cilium structure of adult neural stem cells and adult neurogenesis in mice. Additionally, our results illustrate that Cenpj regulates cilia disassembly and neurogenesis through Kif2a, indicating that primary cilia dynamics play a crucial role in NPC mitosis and adult neurogenesis.

\section{Introduction}

Centrosomes are the organelles at the poles of the spindle that can persist into interphase as microtubule organizing centers. The

Received July 20, 2018; revised Dec. 19, 2018; accepted Dec. 24, 2018.

Author contributions: W.D., Q.W., L.S., N.C.P., and X.W. edited the paper; W.D., Q.W., and X.W. designed research; W.D., Q.W., L.S., N.C.P., and X.W. performed research; X.W. contributed unpublished reagents/analytic tools; W.D., Q.W., L.S., N.C.P., and X.W. analyzed data; W.D., Q.W., and X.W. wrote the paper.

This work was supported by the Strategic Priority Research Program of the Chinese Academy of Sciences (Grant XDA16020601, XDB32010100),the National Basic Research Program of China (Grants 2017 YFA0103303 and 2017YFA0102601), the National Natural Science Foundation of China (Grant 31371100, 31771140, 31671072), and Beijing Brain Initiation (2181100001518004). We thank Bradley Yoder (University of Alabama at Birmingham) for kindly sharing and transferring the mouse strain to us; Tian Xue (University of Science and Technology of China) for sharing the ARPE19 cell line with us; Jianguo Zhang, Lei Sun, and Can Peng (Center for Biological Imaging, Institute of Biophysics, Chinese Academy of Sciences) for help in making EM samples and taking EM images; and Arnold Kriegstein (University of California at San Francisco) and his laboratory members for discussions and reagent support.

The authors declare no competing financial interests.

*W.D. and Q.W. contributed equally to this work. core is a ninefold symmetrical centriole, and their ability to nucleate cytoplasmic microtubules (MTs) is a property of the surrounding pericentriolar material (PCM). The centriole has a dual life, existing not only as the core of the centrosome, but also as the basal body (BB) for primary cilia assembly. As a result, the structure and function of the centriole, the centrosome, and the cilia have an impact on many aspects of development and physiology. The primary cilium, a continuation and extension of microtubule doublets from the BB structure, is localized to the apical region of a radial glial (RG) cell. In the $G_{0}$ quiescent phase, the $R G$ cell processes a primary cilium out of the ventricular end foot surface. Upon entry into the cell cycle, the primary cilium disassembles quickly to release the centrioles to form a bipolar spindle 
(Kobayashi and Dynlacht, 2011; Nigg and Stearns, 2011). Cilium assembly and disassembly are highly correlated to the cell cycle and centrosome (Pugacheva et al., 2007; Qin et al., 2007; Robert et al., 2007). The dynamics of primary cilia, unique in their ability to function as sensors and conveyors of critical signals in a complex environment, may have a supervisory role in the neurogenesis of RG cells.

Mutations of Cenpj or CPAP (a centrosomal-P4.1-associated protein) cause microcephaly, dwarfism, low birthweight, and intellectual disability (Al-Dosari et al., 2010), which are thought to arise from a decline in neural progenitor cells (NPCs) during development (Insolera et al., 2014). Depletion of Cenpj causes severe defects in centriole duplication and increases the population of monopolar, asymmetric bipolar, and multipolar spindles in mitotic cells (Cho et al., 2006; Kohlmaier et al., 2009; Schmidt et al., 2009; Tang et al., 2009; Kitagawa et al., 2011). In addition, Cenpj acts as a scaffold for the cilium disassembly complex, which includes Nde1, Aurora A, and OFD1, which is recruited to the ciliary base for timely cilium disassembly (Gabriel et al., 2016). Mouse embryos with complete elimination of Cenpj present prolonged mitosis and a widespread, p53-dependent cell death phenotype resulting in a reduction in RG cells and other types of NPCs (McIntyre et al., 2012; Bazzi and Anderson, 2014; Insolera et al., 2014; Garcez et al., 2015). A recent study has shown that the cells of cerebral organoids derived from Cenpj-mutant microcephaly patients present long cilia (Gabriel et al., 2016). Contrary to observations in humans, flies with Dsas-4 (the ortholog of Cenpj) mutations show no cilia or flagella (Basto et al., 2006) and deletion of Cenpj by shRNA treatment blocked cilia formation and caused cilia shortening in CAD (Cath. a-differentiated) cells (Wu and Tang, 2012). These observations indicate that Cenpj plays a role in NPC proliferation and cilia formation. However, how the balance between centrosome and cilia functions regulates cortical development is largely unknown.

By conditionally deleting Cenpj in mouse NPCs, we found longer primary cilia and abnormal cilium appendages in RG cells. The defective cilium disassembly upon Cenpj depletion led to reduced cell proliferation, uncompleted cell division, cell apoptosis, and microcephaly in mice. Cenpj depletion also caused long motile cilia with defective structures in ependymal cells and a reduction in adult neural stem cells in mice. Additionally, we found that Kif $2 \mathrm{a}$, a member of the kinesin-13 motor proteins, contributes to Cenpj-regulated cilia disassembly and neurogenesis. These findings indicate that primary cilia dynamics are essential for mitosis of RG cells and are required for constructing a normal cerebral cortex.

\section{Materials and Methods}

Animals. Adult Cenpj ${ }^{\text {LacZ }}$ mice (Cenpj ${ }^{\text {tmla (EUCOMM)Wtsi }}$ ) were obtained from the Welcome Trust Sanger Institute Mouse Genetics Projects. $\mathrm{Cenpj}^{\mathrm{fl} / \mathrm{fl}}$ mice were generated by crossing Cenpj ${ }^{\mathrm{LacZ}}$ mice with Rosa26 ${ }^{\text {Flp }}$ mice. Cenpj ${ }^{\mathrm{fl} /+}$ Emx1-Cre mice were produced by crossing $\mathrm{Cenpj}^{\mathrm{fl} / \mathrm{fl}}$ mice with Emx1-Cre mice. Conditional knock-out (Cenpj ${ }^{\mathrm{CKO}}$ ) mice were produced by crossing Cenpj ${ }^{\mathrm{fl} /+}$ Emxl-Cre mice with Cenpj $^{\mathrm{fl} /+}$ Emx1-Cre mice. Cenpj ${ }^{\mathrm{CKO}} \mathrm{Cilia}^{\mathrm{GFP}}$ mice were obtained by crossing Cenpj ${ }^{\mathrm{fl} /+}$ Emx1-Cre mice with Cilia ${ }^{\text {GFP }}$ mice (R26Sstr3GFP, a gift from Dr. Bradley Yoder at the University of Alabama at Birmingham). Animal housing and experimental procedures in this study were in compliance with the guidelines of the Institutional Animal Care and Use Committee of the Institute of Biophysics, Chinese Academy of Sciences. All mice had ad libitum access to food and water and were housed in the institutional animal care facility (specific pathogen free) with a $12 \mathrm{~h}$ light/dark schedule. Both males and females were used for all experiments.
Cell culture. ARPE19 cells were grown in medium containing DMEM, $10 \%(\mathrm{v} / \mathrm{v}$ ) fetal bovine serum (FBS), $100 \mathrm{U} / \mathrm{ml}$ penicillin, and $100 \mu \mathrm{g} / \mathrm{ml}$ streptomycin (all from Life Technologies). 293T cells were grown under standard conditions in DMEM supplemented with 10\% FBS. For serum starvation experiments, cells were grown in medium without serum for the described time period and stimulated with $10 \%$ FBS-containing medium. Cells were maintained at $37^{\circ} \mathrm{C}$ with $5 \% \mathrm{CO}_{2}$.

Western blotting. The tissue and culture cells were lysed in RIPA (added protease inhibitor). Protein samples were separated by SDS-PAGE and transferred to nitrocellulose membranes. After the nitrocellulose membranes were blocked with $5 \%$ milk for $1 \mathrm{~h}$, the nitrocellulose member was incubated with the primary antibody at $4^{\circ} \mathrm{C}$ overnight and then incubated with horseradish peroxidase-conjugated secondary antibody for $45 \mathrm{~min}$ at room temperature. Enhanced chemiluminescence reagent (Thermo Scientific) was used as a Western blotting substrate to visualizing the protein bands. The antibodies used as follows: GAPDH (1:5000, KC-5G5; KangChen), Cenpj (1:200, 11517-1-AP; Proteintech), and Kif2a (1:5000, PAB12407; Abnova).

Immunostaining. Brain slices were fixed in $4 \%$ paraformaldehyde in PBS, pH 7.4, and culture cells were fixed in ice-cold methanol, permeabilized with $0.1 \%$ Triton X-100 in PBS for 15 min, and blocked with $10 \%$ donkey serum in PBS for $2 \mathrm{~h}$ at room temperature (RT). Antibody incubations were performed overnight at $4^{\circ} \mathrm{C}$ for brain slices or $1 \mathrm{~h}$ at RT for cell cultures, followed by three washes in PBS. Fluorescentconjugated secondary antibody incubation for $2 \mathrm{~h}$ at RT. Images were acquired using a confocal laser scanning microscope (FV1000MPEBX61W1; Olympus) and were analyzed using Fluo View (Olympus) with Imaris (Bitplane) and Photoshop (Adobe Systems) software. Primary antibodies used were as follows: Zo-1 (1:300, 339100; Invitrogen), $\gamma$-Tubulin (1:5000, T3559; Sigma-Aldrich), $\gamma$-Tubulin (1:5000, T5326; Sigma-Aldrich), Acetylated Tubulin (1:30000, T7451; Sigma-Aldrich), Cenpj (1:50, 11517-1-AP; Proteintech), Pericentrin (1:300, 611814; BD Biosciences), GFP (1:500, GFP-1020; Aves Laboratories), Cleaved Caspase 3 (1:300, 9664; Cell Signaling Technology), Tbr2 (1:300, ab23345; Abcam), Satb2 (1:300, ab34735; Abcam), Ctip2 (1:300, ab18465; Abcam), Ki67 (1:300, ab9260; Millipore), BrdU (1:300, ab6326; Abcam), Pax6 (1:300, PRB-278P; Covance), Sox2 (1:300, sc-17320; Santa Cruz Biotechnology), EdU (Click-iT EdU Alexa Fluor 594 Imaging Kit, C10339; Thermo Scientific), GFAP (1:500, G9269,Sigma-Aldrich), and $\beta$-Catenin (1:300, 610153; BD Biosciences). Secondary antibodies used were as follows: donkey anti-mouse, anti-rabbit, anti-chicken, anti-rat or anti-goat Alexa Fluor-546-, Alexa Fluor-488-, and Alexa Fluor-647conjugated antibodies (1:500; Invitrogen). DNA was stained with 49,6diamidino-2-phenylindole (1:10000, D1306; Invitrogen).

Plasmids and in utero electroporation. Cenpj and Kif2a shRNA sequences were cloned into pLL3.7 vector (Addgene, catalog \#11795) as described previously (Wang et al., 2009). Kif2a sequences were cloned into $\mathrm{pEGFP}-\mathrm{C} 1$ vector and ptdTomato-C1 vector. Cenpj sequences were cloned into ptdTomato-C1 vector. Electroporation was performed as described previously (Wang et al., 2009). Briefly, timed pregnant CD-1 mice (E13.5) were deeply anesthetized with isofluorane and the uterine horns were exposed through a midline incision. One microliter of plasmid DNA $(1-2 \mu \mathrm{g} / \mu \mathrm{l})$ mixed with Fast Green (Sigma-Aldrich) was manually microinjected into the brain lateral ventricle through the uterus using a bevelled and calibrated glass micropipette (Drummond Scientific), followed by $550 \mathrm{~ms}$ pulses of $50 \mathrm{mV}$ with a $1 \mathrm{~s}$ interval delivered across the uterus with $29 \mathrm{~mm}$ electrode paddles positioned on either side of the head (BTX, ECM830).

Cortical slice culture and time-lapse imaging. Approximately $12 \mathrm{~h}$ after in utero electroporation, embryos were removed and the brain was extracted into ice-cold artificial CSF (ACSF) containing the following (in mu): $125 \mathrm{NaCl}, 5 \mathrm{KCl}, 1.25 \mathrm{NaH}_{2} \mathrm{PO}_{4}, 1 \mathrm{MgSO}_{4} 2 \mathrm{CaCl}_{2}, 25 \mathrm{NaHCO}_{3}$, and 20 glucose; pH 7.4, 310 mOsm 1-1. Brains were embedded in 3.5\% low-melting-point agarose in ACSF and sectioned at $300 \mu \mathrm{m}$ using a vibratome (Leica microsystems). Brain slices that contained GFPexpressing cells were transferred on to a slice culture insert (Millicell) in a glass-bottom Petri dish (MatTek) with culture medium containing (by volume): $66 \%$ BME, 25\% Hank's, 5\% FBS, 1\% N-2, 1\% penicillin/ streptomycin/glutamine (Invitrogen) and 66\% D- $(+)$-glucose (Sigma- 
Aldrich). Cultures were maintained in a humidified incubator at $37^{\circ} \mathrm{C}$ with constant $5 \% \mathrm{CO}_{2}$ supply. Two hours later, Petri dishes with slice cultures were transferred to an inverted microscope FV1000 (Olympus). Time-lapse images of dividing radial glia cells were acquired every $10 \mathrm{~min}$ for $\sim 5-8 \mathrm{~h}$. Images were analyzed using Fluo View (Olympus) and Photoshop (Adobe Systems).

Real-time PCR assay. Total RNA was extracted from cells by using SV Total RNA Isolation System (Promega). Reverse transcription was performed with the Prime Script II first Strand cDNA Synthesis Kit (Takara) and real-time PCR was performed by using SYBR Premix Ex Taq (Tli RNaseH Plus; Takara). The real-time PCR contained $5 \mu$ l of qPCR Mix, $0.4 \mu \mathrm{l}$ of forward primer, $0.4 \mu \mathrm{l}$ of reverse primer, $1 \mu \mathrm{l}$ of cDNA template, and $3.2 \mu \mathrm{l}$ of $\mathrm{ddH}_{2} \mathrm{O}$ and in the following conditions: $95^{\circ} \mathrm{C}$ for $30 \mathrm{~s}$, followed by 40 cycles of $95^{\circ} \mathrm{C}$ for $5 \mathrm{~s}, 60^{\circ} \mathrm{C}$ for $10 \mathrm{~s}$, and $72^{\circ} \mathrm{C}$ for $15 \mathrm{~s}$. The data were normalized to that of the internal control. Primer sequences are described in the supplemental information.

RNA-sequencing (RNA-Seq) and library construction. For RNA-Seq analysis, a timed pregnant mouse at E15.5 were anesthetized. Embryos were removed separately and genotyping was performed to identify the $\mathrm{Cenpj}^{\mathrm{f} /+}$ and Cenpj ${ }^{\mathrm{CKO}}$ pups. Cortical slices of Cenpj ${ }^{\mathrm{f} /+}$ and Cenpj ${ }^{\mathrm{CKO}}$ embryos were prepared as described above. The ventricular zone (VZ)/ subventricular zone (SVZ) regions were dissected separately and RNA was isolated using RNeasy Mini kit (Qiagen) according to the manufacturer's instructions. After the samples were tested, the eukaryotic mRNA was enriched by magnetic beads with Oligo (dT). Subsequently, using fragmentation buffer to break the mRNA into short fragments, $t$ mRNA was used as a template to synthesize a strand of cDNA with six random bases and then the buffer, dNTPs, and DNA polymerase I were used to synthesize the double-stranded cDNA, followed by AMPure XP beads of purified double-stranded cDNA. The purified double-stranded cDNA was subjected to terminal repair, a tail was added, and the sequencing adapter was ligated. The size of the fragment was then selected with AMPure XP beads and, finally, PCR enrichment was performed to obtain the final cDNA library. RNA-Seq was performed by the Novogene Bioinformatics Institute, Beijing.

Scanning electron microscopy. Mice were anesthetized and perfused with $0.1 \mathrm{M}$ PBS buffer $\mathrm{pH} 7.4$ containing $2.5 \%$ glutaraldehyde (Electron Microscopy Sciences) and 2\% formaldehyde (Sigma-Aldrich). Brains were then removed and fixed overnight in the same solution at $4^{\circ} \mathrm{C}$ and cut into $500-\mu \mathrm{m}$-thick vibratome sections in PBS, washed three times with PBS, and then dehydrated through an ethanol gradient $(30 \%, 60 \%$, $90 \%$, and $100 \%$ ). Samples were dried without introducing surface tension artifacts by using critical point drier. After drying, samples were then introduced into the chamber of the sputter coater and coated with a very thin film of gold before SEM examination. 3D reconstruction was analyzed by Amira and Imaris.

Transmission electron microscopy. Mouse embryos were perfused with $2 \%$ glutaraldehyde and $2 \%$ paraformaldehyde in PBS and then fixed in perfusion solution overnight at $4^{\circ} \mathrm{C}$. The samples were washed 3 times with PBS then secondarily fixed in $2 \%$ osmium tetroxide (SigmaAldrich) in cacodylate buffer for $2 \mathrm{~h}$ at room temperature. The samples were washed three times with $\mathrm{ddH}_{2} \mathrm{O}$, stained with uranyl acetate then dehydrated through an ethanol gradient $(30 \%, 60 \%, 90 \%$, and $100 \%)$ followed by propylene oxide. Subsequently, samples were embedded in low-viscosity resin (TAAB Laboratories). Sections were cut on a microtome (Leica, EM UC6 + FC6) and then viewed on a transmission electron microscope (Tecnai Spirit, $120 \mathrm{kV}$ ).

$3 D$ model reconstruction. We took serial images of the brain tissue at 80 $\mathrm{nm}$ intervals with a focused ion beam scanning electron microscope (FIB-SEM). We manually drew the morphology of the cilium of the ependymal cells in each image and then created a surface using these consecutive pictures by Imaris software. A surface represents a cilium. All cilia were drawn in this manner. Multicilia 3D morphology of ependymal cells was reconstructed.

Quantification of polarity defects. We used the algorithm previously published for the characterization of PCP (Planar Cell Polarity) defects in the same system (Boutin et al., 2014). For the analysis of translation polarity defects in ependymal multiciliated cells, we imported images into MATLAB and saved regions of interest. Then we traced the cell borders and basal body based on Zo-1 and $\gamma$-tubulin staining respectively. Centers of mass were calculated for BBs and cellular outline within every cell. Angles of $\mathrm{BB}$ orientation vectors (BBOVs) were measured and CSD across all BBOVs within every field of view was assessed. Each experimental condition was characterized by mean and CSDs across all fields of view. CSD values were calculated for BBOV angles. The angles measured within one image plane were normalized by subtracting from their values the average angle of a corresponding field of view, this difference was added to $90^{\circ}$ and plotted on the summarized graph.

Statistical analysis. All data were represented as the mean \pm SD. Comparisons between two groups were performed using $t$ tests. The quantification of polarity defects used an unpaired Mann-Whitney test. The quantification graphs were analyzed by using GraphPad Prism software. Sample size and $p$-values are described in the figure legends. Differences were considered significant at $p<0.05$.

\section{Results \\ Cenpj deletion in mice causes abnormal cilia and microcephaly}

To define the function of Cenpj in ciliogenesis in vivo and the cellular basis of centrosome-associated microcephaly, Cenpj ${ }^{\mathrm{CKO}}$ mice were developed by crossing Cenpj ${ }^{\mathrm{fl} / \mathrm{fl}}$ mice with Emx1-Cre mice, which selectively express Cre recombinase in dorsal telencephalic NPCs (Fig. 1A). Western blot analysis of the mouse cortex lysate at E15.5 confirmed that the expression of Cenpj was depleted in the Cenpj ${ }^{\mathrm{CKO}}$ cortex (Fig. $1 B, C$ ). Brain sections were immunostained for Cenpj and pericentrin, a pericentriolar material protein, and no Cenpj signals were detected in centrosomes on the VZ (Fig. 1D). With Cenpj deletion in NPCs of the dorsal telencephalon, the brain hemisphere circumference of Cenpj ${ }^{\mathrm{CKO}}$ embryos was greatly decreased compared with that of the control Cenpj $^{+/+}$embryos at E15.5 (Fig. 1E,F). Nissl staining of brain slices at E15.5 revealed significantly reduced thickness of the cortex with a normal layered structure upon Cenpj depletion (Fig. $1 G, H)$. We also checked the cortical development of the Cenpj $^{+/+}$and Cenpj ${ }^{\mathrm{CKO}}$ cortex at P7. Although body size was not influenced by Cenpj depletion, a reduced brain size, smaller hemisphere circumference and thinner cortex were observed in the Cenpj ${ }^{\mathrm{CKO}}$ mice (Fig. $\left.1 I-K\right)$. The numbers of early-born Ctip2-expressing deep layer neurons and late-born Statb2expressing superficial layer neurons were both reduced in the Cenpj ${ }^{\mathrm{CKO}}$ cortex (Fig. $\left.1 L, M\right)$. Consistently, we observed a decrease in Foxp2-expressing layer VI neurons and Cux1expressing layer II/III neurons following Cenpj depletion but with normal lamination (Fig. $1 N-P$ ). The phenotypes were consistent with the phenotypes of microcephaly patients caused by Cenpj mutations (Leal et al., 2003; Gul et al., 2006; Al-Dosari et al., 2010); therefore, we used the mouse model to investigate Cenpj-related microcephaly pathogenic mechanisms.

To detect the cilia in vivo, a Cre recombinase-inducible Cilia ${ }^{\text {GFP }}$ mouse (O'Connor et al., 2013) was used. Cenpj ${ }^{\text {CKO Cilia GFP }}$ RG cells had longer cilia than Cenpj ${ }^{+/+}$Cilia $^{\text {GFP }}$ RG cells (Fig. $2 A, B)$. As observed by scanning electron microscope, RG cells of the Cenpj ${ }^{\mathrm{CKO}}$ mice consistently contained long cilia with a median length of $1.93 \pm 0.29 \mu \mathrm{m}$ compared with RG cells of Cenpj ${ }^{+/+}$mice, which contained cilia with a median length of $1.11 \pm 0.15 \mu \mathrm{m}$ at E15.5 (Fig. 2C,D). At the end of cortical development, monociliated progenitor cells in the VZ differentiate into multiciliated ependymal cells (Spassky et al., 2005). Therefore, an FIB-SEM was used to capture serial images at $80 \mathrm{~nm}$ intervals. Multicilia 3D morphology of ependymal cells was reconstructed (Fig. 2E, Movies 1, 2, 3, 4). The reconstructed images showed that the motile cilia length $(11.4 \pm 1.6 \mu \mathrm{m})$ of ependymal cells was increased in Cenpj ${ }^{\mathrm{CKO}}$ mice compared with that in 
A

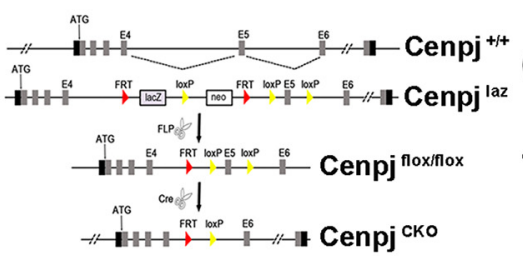

B

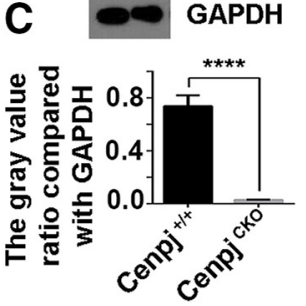

E

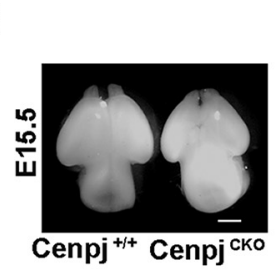

$\mathbf{F}$

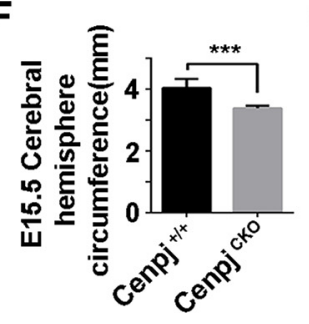

G Cenpj $^{+/+}$

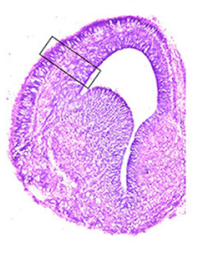

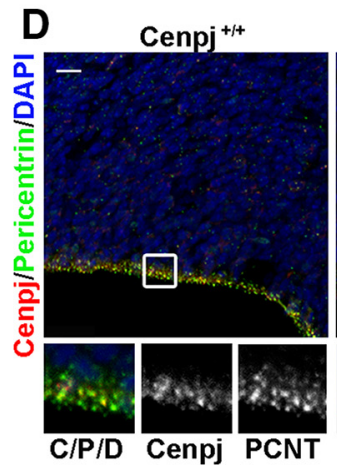

Cenpj ${ }^{\text {ско }}$

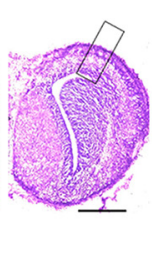

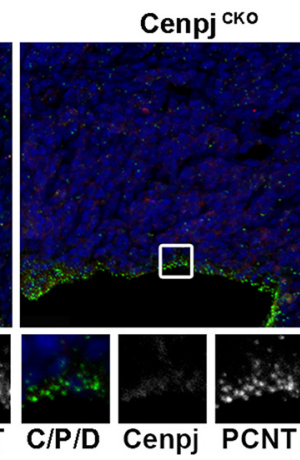

$\mathrm{H}$

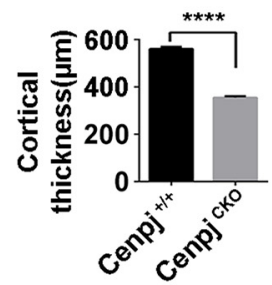

\section{I}

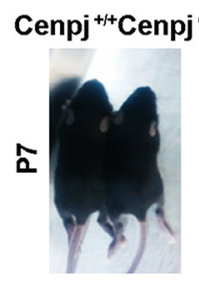

$\mathbf{L}$

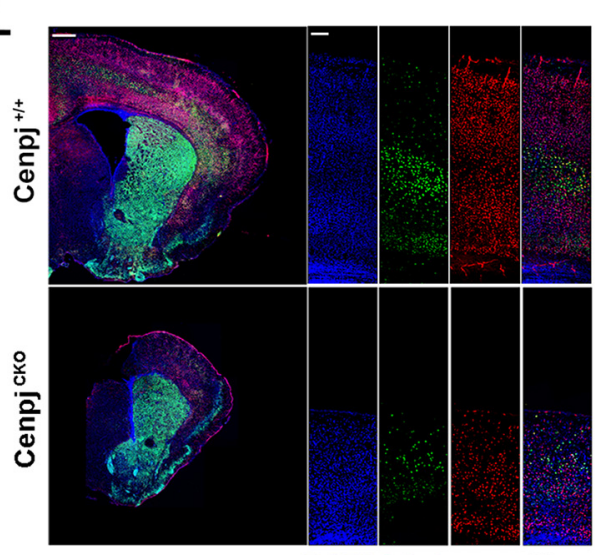

DAPI Ctip2 Satb2Merge
$\mathbf{K}$

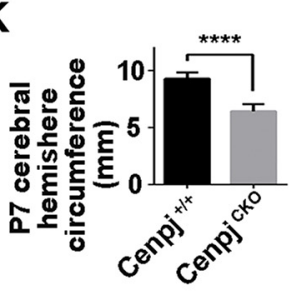

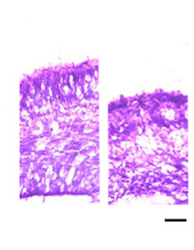

M

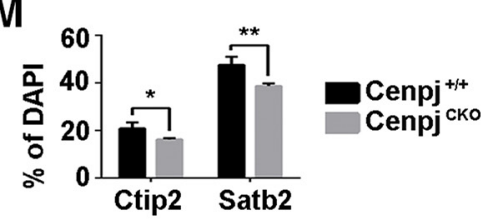

$\mathbf{N}$

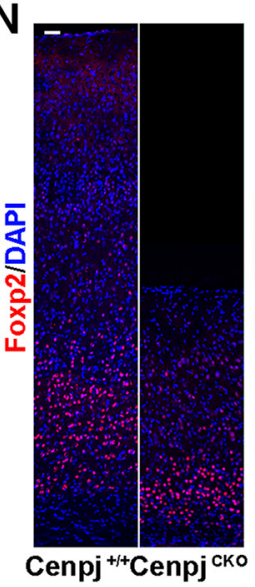

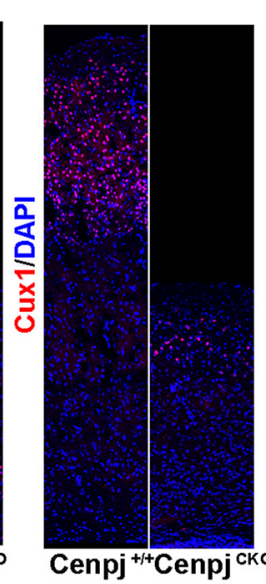

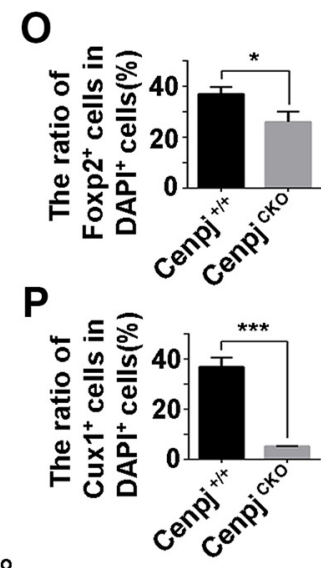

Figure 1. Cenpj was specifically depleted in the dorsal telencephalon of Cenpj ${ }^{\mathrm{K} 0}$ mice. $A$, Schematic of Cenpj-trapped mice construction strategy. A LacZ reporter cassette and a neo tag, flanked by two FRT sequences, were introduced between the fourth exon and the fifth exon of Cenpj gene locus. The fifth exons were flanked by two LoxP sites in Cenpj ${ }^{\text {LacZ }}$ mice. LacZ reporter cassettes can be removed by Flippase splicing and the Cenpj gene can be knocked out by tissue-specific Cre recombinase splicing. B, Western blot analysis for Cenpj ${ }^{+/+}$and Cenpj ${ }^{\text {CKO }}$ cerebral cortex lysate at E15.5. C, Quantification of Cenpj knock-out by Western blot. Histogram shows the mean $\pm S D ; * * * p<0.0001$ as determined by a $t$ test; $n=3$. D, Brain sections were immunostained by anti-Pericentrin (green) antibody and anti-Cenpj (red) antibody on the ventricular surface in Cenpj ${ }^{+/+}$and Cenpj ${ }^{\mathrm{CK} 0}$ mice. Scale bar, $10 \mu \mathrm{m} . \boldsymbol{E}$, Representative whole-mount images of Cenpj ${ }^{+/+}$ and Cenpj ${ }^{\mathrm{CKO}}$ brains at E15.5. Scale bar, $0.5 \mathrm{~mm}$. $\boldsymbol{F}$, Quantification of cerebral hemisphere circumference at E15.5. Data are presented as the mean $\pm \mathrm{SD}$; ${ }^{* * *} p=0.0004$ as determined by a $t$ test; $n=3 . G$, Representative images of Cenpj ${ }^{+/+}$and Cenpj ${ }^{\text {CKO }}$ brain coronal sections at E15.5 by Nissl staining. Right, Magnified cortical column. Scale bars, $500 \mu \mathrm{m}$ (left) and $100 \mu \mathrm{m}$ (right). $\boldsymbol{H}$, Histogram of the cerebral cortex thickness. Data are presented as the mean $\pm S D ;{ }^{* * * *} p<0.0001$ as determined by a $t$ test; $n=3 ; 3$ brain slices per experiment. $I$, Body size of Cenpj ${ }^{+/+}$and Cenpj ${ }^{\mathrm{CK} 0}$ mice at P7.J, Representative images of the Cenpj ${ }^{+/+}$and Cenpj ${ }^{\mathrm{CK} 0}$ brain size at P7. Scale bar, $1 \mathrm{~mm}$. $\boldsymbol{K}$, Quantification of P7 cerebral hemisphere circumference. Data are presented as the

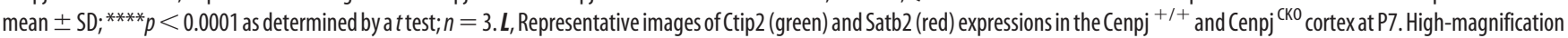
images show the cortical column. Scale bar, $30 \mu \mathrm{m} . \boldsymbol{M}$, Quantification of Ctip2 ${ }^{+}$cells and Satb2 ${ }^{+}$cells ratios in the neocortex. Data are presented as the mean $\pm S D ;{ }^{*} p_{\text {ctip } 2}=0.0335,{ }^{* *} p_{\text {Satb2 }}=$ 0.0011 as determined by a $t$ test; $n=3 ; 3$ brain slices per experiment. $\boldsymbol{N}$, Representative images of Foxp2 and Cux1 expressions in the Cenpj ${ }^{+/+}$and Cenpj ${ }^{\text {CK0 }}$ cortex at P7. Scale bar, $30 \mu \mathrm{m}$. $\mathbf{0}$, Quantification of Foxp2 ${ }^{+}$cells ratios in the neocortex. Data are presented as the mean $\pm \mathrm{SD} ;{ }^{*} p=0.0175$, as determined by a $t$ test; $n=3 ; 3$ brain slices per experiment. $\boldsymbol{P}$, Quantification of Cux $1^{+}$cells ratios in the neocortex. Data are presented as the mean $\pm S D ; * * * p=0.0001$ as determined by a $t$ test; $n=3 ; 3$ brain slices per experiment. 
A

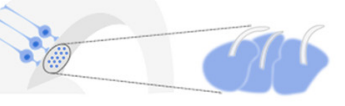

B
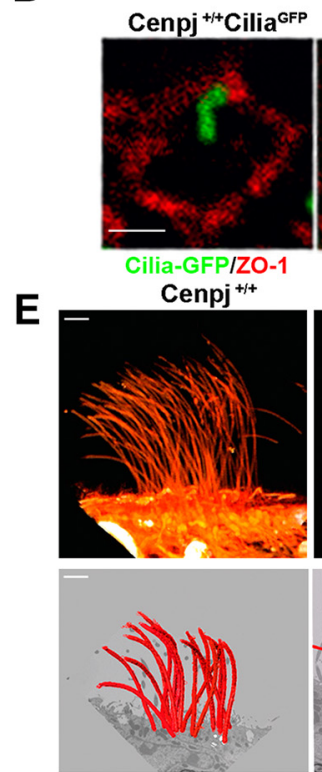

$\mathbf{F}$

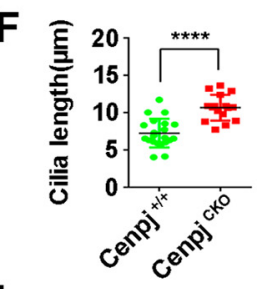

I Cenpj ${ }^{++}$
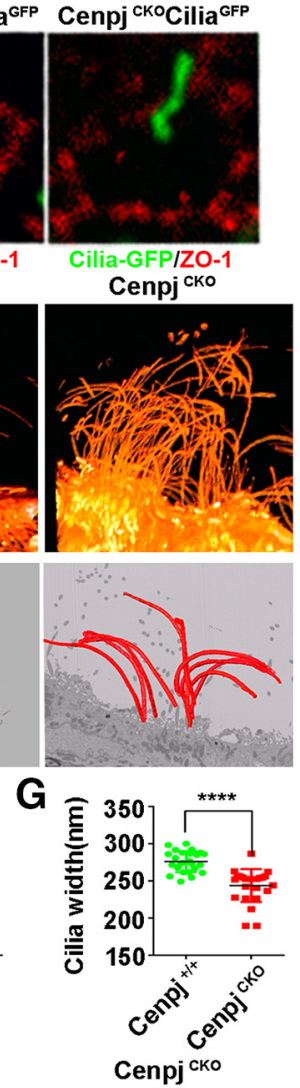

Cilia-GFPIZO-1
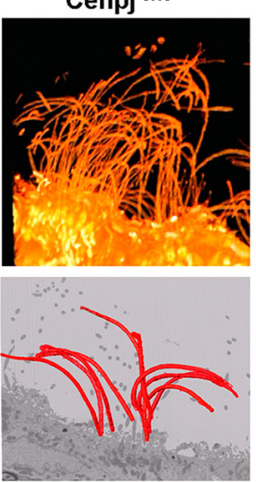

C

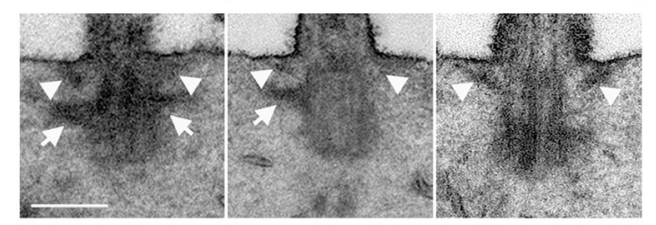

K Cenpj $^{+*+}$

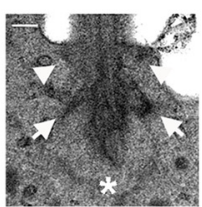

Cenpj ${ }^{\text {ско }}(97.9 \%)$

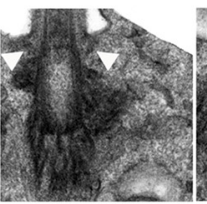

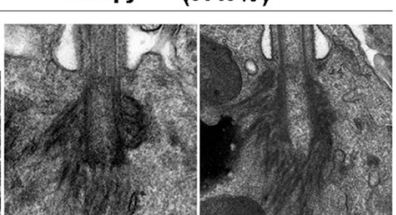
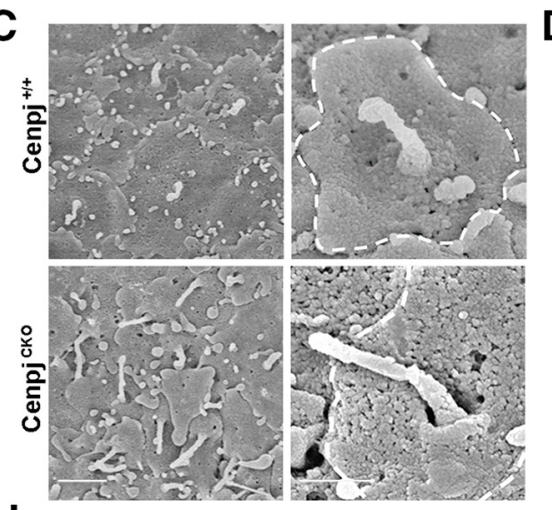

D
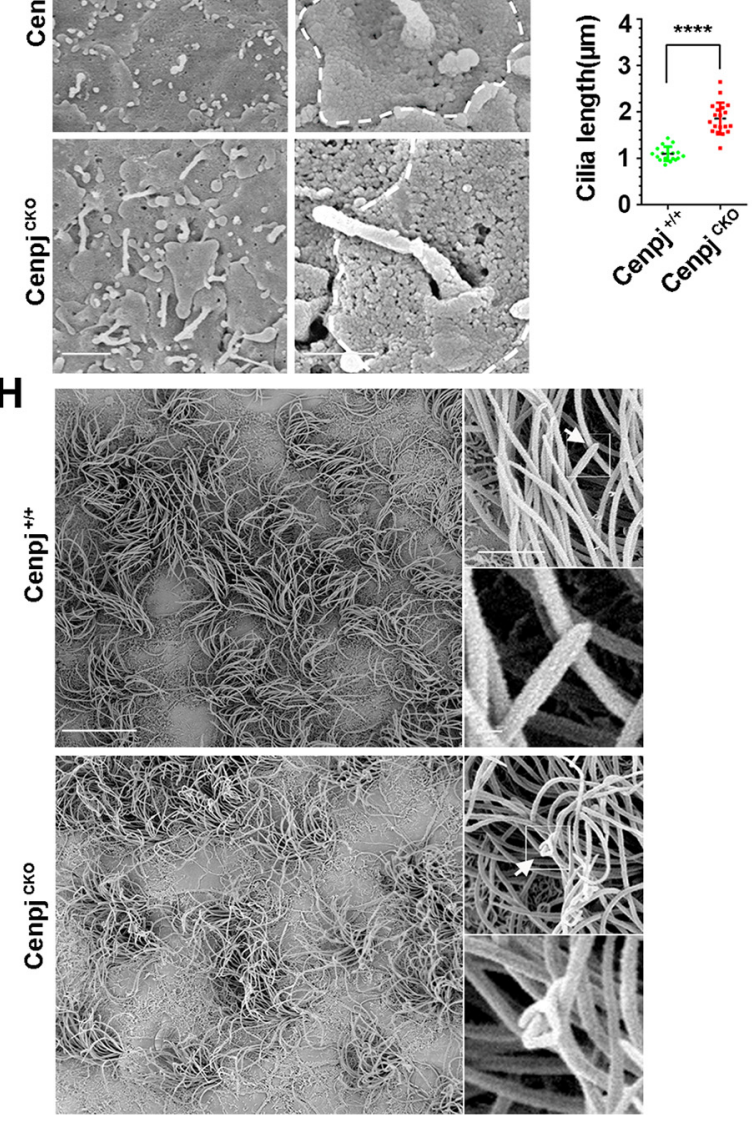

J Cenpj $^{+/+} \quad$ Cenpj $^{\text {cko }}$

$L$ Cenpj $^{+/+}$Cenpj ${ }^{\text {cko }}$
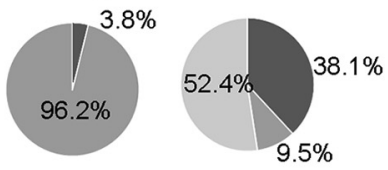

normal lack one appendage lack two or more appendage

M
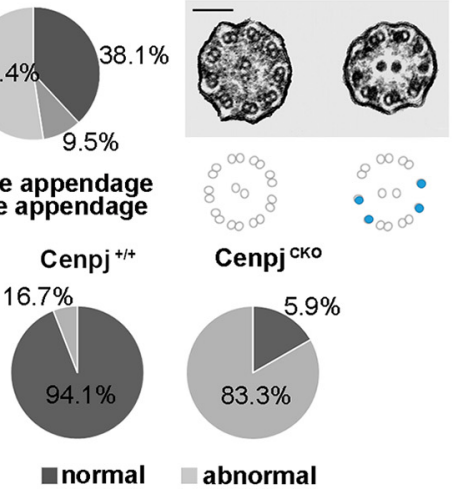

Cenpj ${ }^{\text {ско }}$

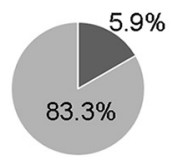

abnormal

Figure 2. Deletion of the centrosome protein Cenpj causes overly long cilium and abnormal cilium appendages. $A$, Model showing the primary cilium on the end foot of RG cells on the lateral ventricle surface. $\boldsymbol{B}$, Whole-mount immunostaining images showing that Cenpj ${ }^{\mathrm{CKO}}$ cilia are longer than Cenpj ${ }^{+/+}$cilia at E15.5. Tight junction protein Z0-1 (red) marks the cell membrane of the RG end foot. Scale bar, $1 \mu \mathrm{m}$. C, Scanning electron microscope images of the ventricular surface of Cenpj ${ }^{+/+}$and (enpj ${ }^{\text {CK0 }}$ embryo brains at E15.5. Scale bars, $2 \mu \mathrm{m}$ (left) and $1 \mu \mathrm{m}$ (right). $D$, Quantification of the cilia length in a scatter plot showing the mean $\pm S D ;{ }^{* * * *} p<0.0001$ as determined by a $t$ test. $E$, Two ways of reconstructing SEM serial sections of the ventricular surface of Cenpj ${ }^{+/+}$and Cenpj ${ }^{\mathrm{CKO}}$ adult mouse brain. Scale bar, $2 \mu \mathrm{m}$. $\boldsymbol{F}$, Quantification of the cilia length in a scatter plot showing the mean $\pm S D$; $* * * * p<0.0001$ as determined by a $t$ test. G, Quantification of the cilia width in a scatter plot showing the mean \pm SD; ${ }^{* * * *} p<0.0001$ as determined by a $t$ test. $\boldsymbol{H}$, SEM images of the Cenpj ${ }^{+/+}$and Cenpj ${ }^{\mathrm{CK} 0}$ adult brain ventricular surface. The motile cilia are magnified. Arrow shows the cilia tip. Scale bars, $10 \mu \mathrm{m}$ (left and right top) and $1 \mu \mathrm{m}$ (right bottom). $I$, Transmission electron microscope images of Cenpj ${ }^{+/+}$and Cenpj ${ }^{\text {CKO }}$ cilium appendages of RG at E15.5. Distal appendages (arrowhead) and subdistal appendages (arrow) in Cenpj ${ }^{+/+}$and Cenpj ${ }^{\mathrm{CKO}} \mathrm{BBs}$. Scale bar, $250 \mathrm{~nm}$. J, Percentages of normal and abnormal cilium in Cenpj ${ }^{+/+}$and Cenpj ${ }^{\mathrm{C} 0}$ mouse embryo RG cells. $\boldsymbol{K}$, Transmission electron microscope images of Cenpj ${ }^{+/+}$and Cenpj ${ }^{\mathrm{CK} 0}$ adult cilia appendages. Normal distal appendages (arrowhead) and subdistal appendages (arrow) in Cenpj ${ }^{+/+}$cilia. Asterisk shows striated rootlets. Scale bar, $100 \mathrm{~nm}$. $L$, Transmission electron microscope images of Cenpj ${ }^{+/+}$and Cenpj $^{\text {CKO }}$ adult cilia

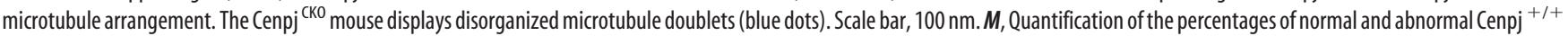
or Cenpj ${ }^{\mathrm{CK} 0}$ adult cilia microtubule arrangement. 


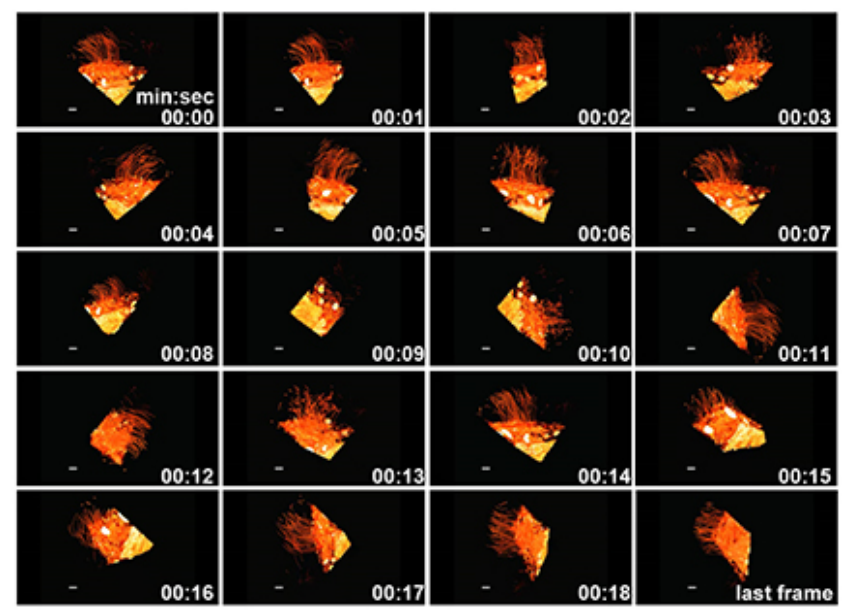

Movie 1. Movie related to Fig. 2E showing 3D reconstruction of the ependymal cell multicilia morphology of the Cenpj ${ }^{+/+}$adult mouse brain by Amira composed of 143 images with $80 \mathrm{~nm}$ intervals. Scale bar, $2 \mu \mathrm{m}$.
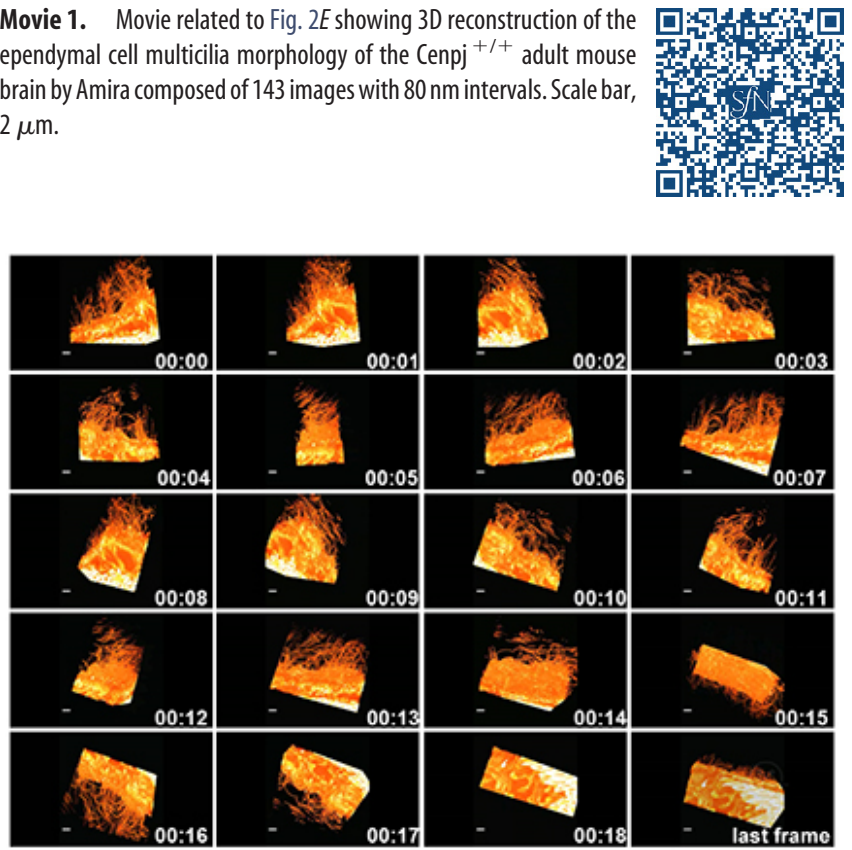

Movie 2. Movie related to Fig. 2E showing 3D reconstruction of the ependymal cell multicilia morphology of the Cenpj ${ }^{\mathrm{CK} 0}$ adult mouse brain by Amira composed of 131 images with $80 \mathrm{~nm}$ intervals. Scale bar, $2 \mu \mathrm{m}$.

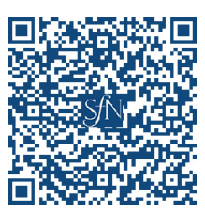

Cenpj $^{+/+}$mice $(7.2 \pm 2.5 \mu \mathrm{m}$ ) (Fig. $2 E, F)$. In addition, Cenpj ${ }^{\mathrm{CKO}}$ cilia were disarrayed on the cell surface compared with organized Cenpj ${ }^{+/+}$cilia (Fig. 2E). The diameters of the Cenpj ${ }^{\mathrm{CKO}}$ cilia were smaller than those of the Cenpj ${ }^{+/+}$cilia (Fig. $2 G)$. Furthermore, on the adult brain ventricle surface of Cen$\mathrm{pj}^{\mathrm{CKO}}$ mice, the motile cilia were curled and tangled with bulges and curly tips when observed by scanning electron microscope (Fig. $2 \mathrm{H}$, arrow).

Cilia emerge from a tubulin-based structure called the BB (Yang et al., 2005; Mohan et al., 2013). Ultrastructural analysis revealed that the majority of primary cilium BBs of Cenpj ${ }^{\mathrm{CKO}} \mathrm{RG}$ cells lacked one or more appendages, including distal appendages (arrowhead) and subdistal appendages (arrow), at E15.5 (Fig. $2 I, J)$. Similarly, the ultrastructure of the motile cilia appendages in adult ependymal cells exhibited abnormal organization upon Cenpj depletion. Unlike the wild-type mice, which had distal and

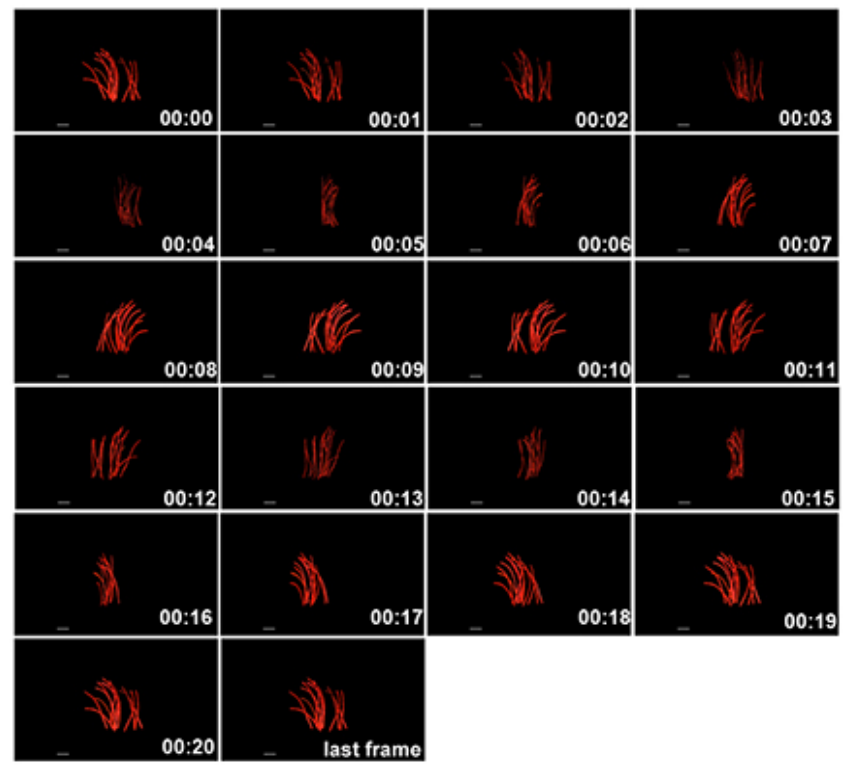

Movie 3. Movie related to Fig. $2 E$ showing $3 D$ reconstruction of the $\square$ ependymal cell multicilia morphology of the Cenpj $^{+/+}$adult mouse brain by Imaris composed of 143 images with $80 \mathrm{~nm}$ intervals. Scale bar, $2 \mu \mathrm{m}$.

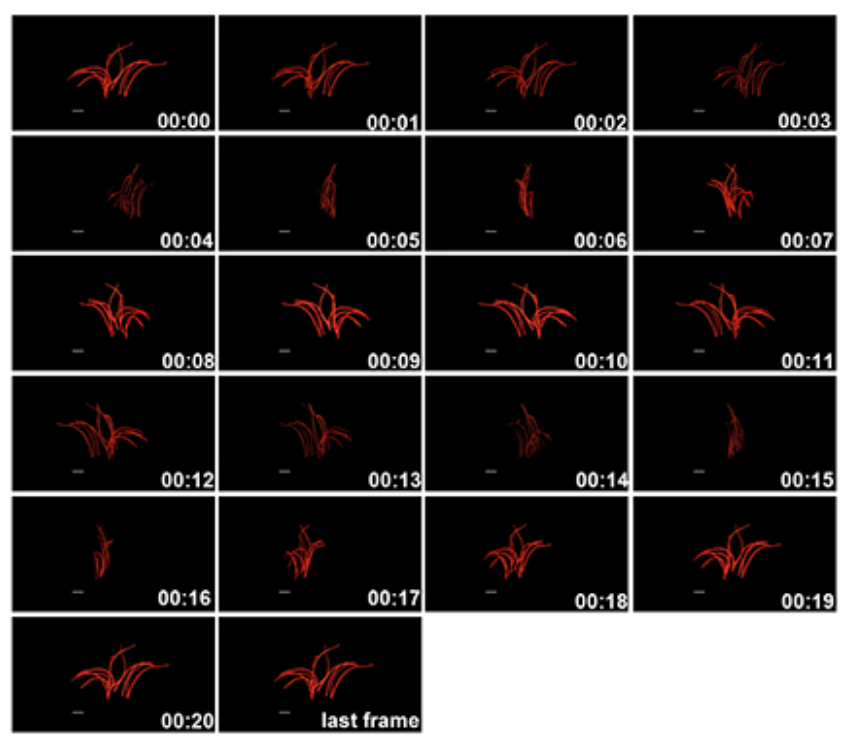

Movie 4. Movie related to Fig. 2E showing $3 \mathrm{D}$ reconstruction of the ependymal cell multicilia morphology of the Cenpj ${ }^{\text {CKO }}$ adult mouse brain by Imaris composed of 131 images with $80 \mathrm{~nm}$ intervals. Scale bar, $2 \mu \mathrm{m}$.

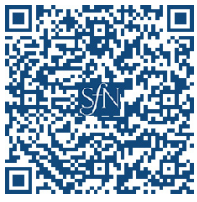

subdistal appendages, the appendages of Cenpj ${ }^{\mathrm{CKO}}$ mice were hair-like with some parts gathered into a bulging shape. We found $\sim 97.9 \%$ of RG cells with abnormally disorganized appendages, including distal appendages (arrowhead) and subdistal appendages (arrow), and striated rootlets (asterisks) in the SVZ of adult Cenpj ${ }^{\mathrm{CKO}}$ mice (Fig. $2 \mathrm{~K}$ ). The aberrant arrangement of the microtubule doublets was also observed in Cenpj ${ }^{\mathrm{CKO}}$ motile cilia by transmission electron microscopy (Fig. $2 L, M$ ). Together, these results suggest that Cenpj plays a role in regulating cilia 

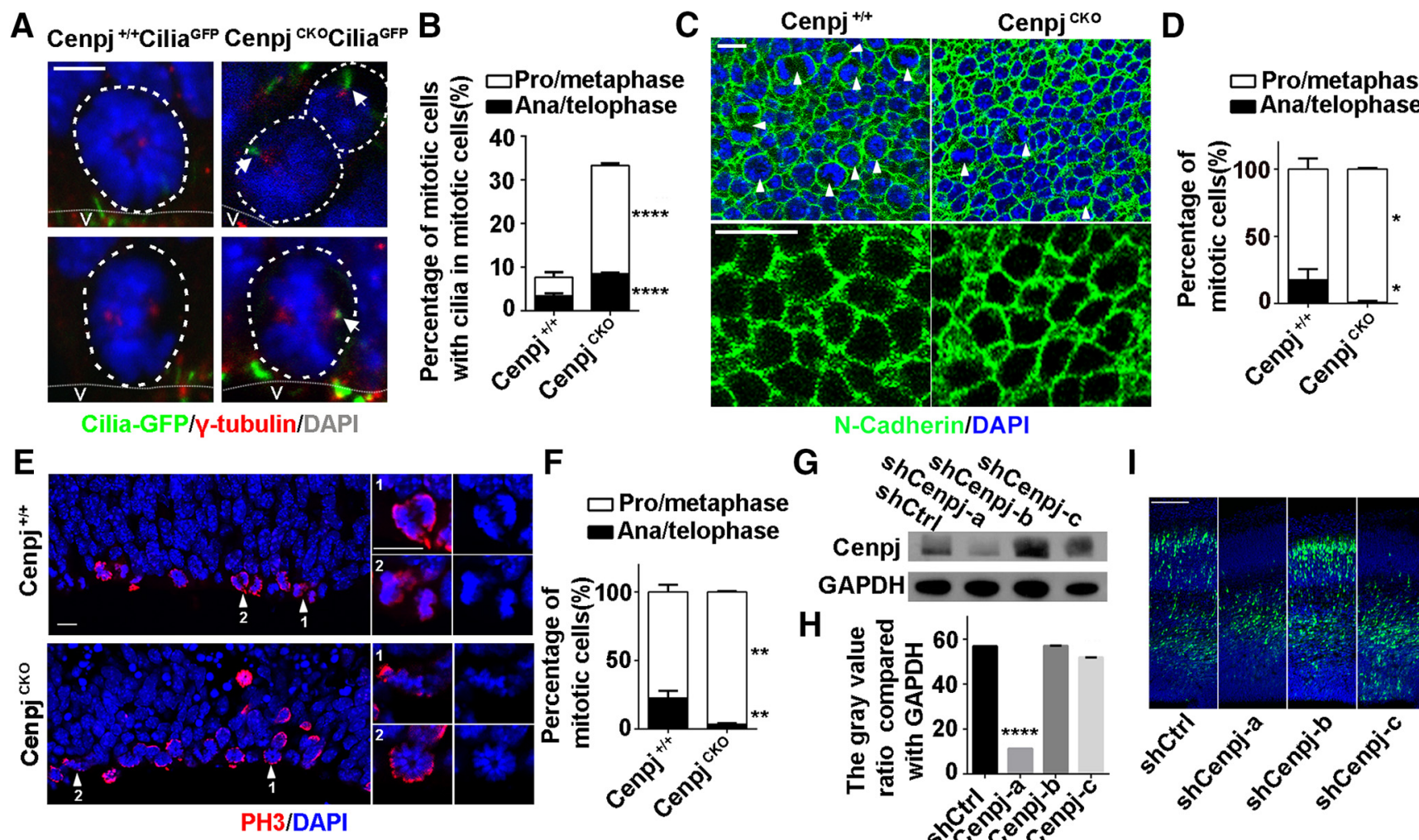

N-Cadherin/DAPI
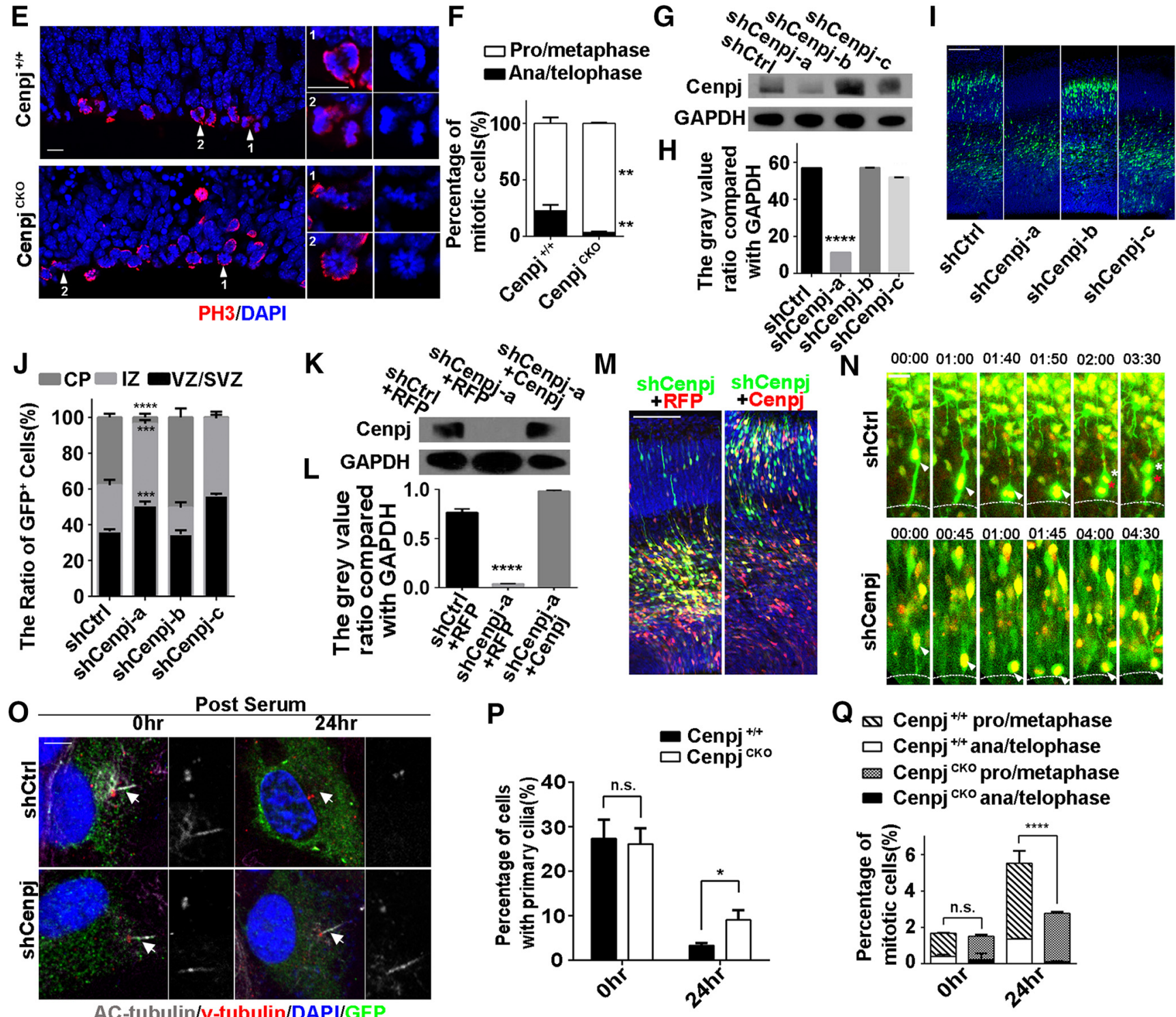

$\mathbf{Q} \otimes$ Cenpj $^{+/+}$pro/metaphase

$\square$ Cenpj $^{+/+}$ana/telophase

Cenpj ${ }^{\mathrm{cko}}$ pro/metaphase

- Cenpj ${ }^{\text {ско }}$ ana/telophase

AC-tubulin/y-tubulin/DAPI/GFP

Figure 3. Cenpj regulates cilia disassembly and RG division. $A$, Representative images of the mitotic cells on the lateral ventricle surface of Cenpj ${ }^{+/+} \mathrm{Cilia}^{\text {GFP }}$ and Cenpj ${ }^{\text {CK0 }}$ Cilia ${ }^{\text {GFP }}$ embryo brains. Cilia are shown in green and $\gamma$-tubulin in red. Scale bar, $10 \mu \mathrm{m}$. B, Quantification of the mitotic cells with cilia in prophase/metaphase versus in anaphase/telophase on the Cenpj ${ }^{+/+}$and Cenpj ${ }^{\text {CK }}$ mouse lateral ventricle surface. Histogram showing the mean $\pm \mathrm{SD} ;{ }^{* * * *} p_{\text {prophase/metaphase }}<0.0001,{ }^{* * * *} p_{\text {anaphase/telophase }}<0.0001$ as determined by $t$ test; $n=3 ;>200$ cells per experiment. C, En face views of the embryo ventricular zone in Cenpj ${ }^{+/+}$and Cenpj ${ }^{\text {(Ko }}$ mice stained for $\mathrm{N}$-cadherin (green) and DAPI (blue). High-magnification images indicate cell adhesion. Arrowheads indicated the mitotic cells. Scale bar, $10 \mu \mathrm{m}$. D, Quantification of the mitotic cells in pro/metaphase versus those in anaphase/telophase on the Cenpj ${ }^{+/+}$and Cenpj ${ }^{\mathrm{CKO}} \mathrm{mouse} \mathrm{lateral} \mathrm{ventricle}$ surface. Histogram showing the mean $\pm S D ;{ }^{*} p_{\text {prophase/metaphase }}=0.0230,{ }^{*} p_{\text {anaphase/telophase }}=0.0230$ as determined by $t$ test; $n=3 ; 3$ brain slices per experiment. $\boldsymbol{E}$, Representative images of mitotic cells at the VZ surface in E13.5 Cenpj ${ }^{+/+}$or Cenpj ${ }^{\text {KO }}$ cortices stained for phosphorylated histone 3 (H3, red) and DAPI (blue). High-magnification images indicate mitotic cells. Scale bar, $10 \mu \mathrm{m}$. $\boldsymbol{F}$, Quantification of the fraction of mitotic cells in prophase/metaphase (white) versus those in anaphase/telophase (black), which reflects mitotic progression. Histogram showing the means $\pm S D ;{ }^{* *} p_{\text {prophase/metaphase }}=0.0037,{ }^{* *} p_{\text {anaphase/telophase }}=0.0037$ as determined by $t$ test; $n=3 ;>200$ cells per experiment. G, (enpj was efficiently knocked down by Cenpj shRNAs. GAPDH serving as a loading control. $\boldsymbol{H}$, Quantification of Cenpj knockdown efficiency by shRNAs. Histograms show the mean \pm SD; ${ }^{* * * *} p_{\text {shctrl vs shcenpj-a }}<0.0001$, (Figure legend continues.) 
structural elements, including length, width, microtubule structure, and appendage organization, in embryonic and adult NPCs.

Cenpj controls NPC division by regulating cilia disassembly It has been demonstrated that ciliary dynamics, including assembly and disassembly, can affect the timing of the cell cycle (Kim and Tsiokas, 2011; Basten and Giles, 2013). Previous research has suggested that primary cilia disassemble when cells enter mitosis to release the centrosome to assemble the spindle body (Wang et al., 2014). Consistent with previous observations (Paridaen et al., 2013 ), we found $\sim 8.2 \%$ RGCs with disassembled cilia by immunostaining of $\gamma$-tubulin in the RG cells of $\mathrm{Cenpj}^{+/+} \mathrm{Cilia}^{\mathrm{GFP}}$ mice, but this number increased dramatically to $33.8 \%$ of Cenpj ${ }^{\mathrm{CKO}}{ }^{\mathrm{Cilia}}{ }^{\mathrm{GFP}} \mathrm{RG}$ cells at E15.5 (Fig. $3 A, B$ ). Consistently, en face views of the VZ showed an increased percentage of prophase and metaphase RG cells and a decreased percentage of anaphase and telophase RG cells on the VZ surface upon Cenpj depletion (Fig. $3 C, D$ ). However, Cenpj depletion has no obvious effect on cell-cell adhesion of RG cells as shown by $\mathrm{N}$-cadherin immunofluorescent staining (Fig. 3C). To further observe dividing cells, immunostaining of phosphorylation of histone $\mathrm{H} 3$ was used to label mitotic RG cells. We observed that more dividing cells were in prophase and metaphase in the Cenpj ${ }^{\mathrm{CKO}} \mathrm{VZ}$ compared with the Cenpj ${ }^{+/+}$VZ (Fig. $3 E, F$ ), suggesting that the disassembly of cilia blocked the cell cycle of RG cells.

Next, we evaluated whether Cenpj depletion delays the mitosis of RG cells. We first reduced Cenpj expression by shorthairpin RNAs (shCenpj-a, shCenpj-b and shCenpj-c; Fig. 3G,H). Cenpj shRNA constructs were electroporated into the mouse cortex via in utero electroporation (IUE) at E13.5 and the brains were examined $3 \mathrm{~d}$ later (E16.5). In contrast to shControl-GFPelectroporated samples, most of the shCenpj-GFP-transfected cells were found in the intermediate zone, suggesting that Cenpj depletion impairs neurogenesis, possibly including migration (Fig. 3I,J). This neurogenesis defect was rescued by exogenous expression of Cenpj-tdTomato plasmid (Fig. $3 K-M$ ). Highefficiency shCenpj-a was selected to be electroporated at E13.5 and cell divisions of RG cells were recorded by time-lapse microscopy. Compared with normal interkinetic nuclear migration and mitosis, RG cells stayed in prophase/metaphase for an abnor-

$\leftarrow$

(Figure legend continued.) as determined by $t$ test; $n=3 . I$, Analysis of the radial migration of cortices $3 \mathrm{~d}$ after IUE at E13.5. Scale bar, $30 \mu \mathrm{m}$. J, Quantification of the neurogenesis after silencing Cenpj by measuring the percentages of $\mathrm{GFP}^{+}$cells that have reached different zones of the cortex $3 \mathrm{~d}$ after electroporation. Histograms show the mean \pm SD; shCtrl vs shCenpj-a $\left({ }^{* * * *} p_{\mathrm{CP}}<0.0001,{ }^{* * *} p_{\mathrm{IZ}}=0.0008,{ }^{* * *} p_{\mathrm{VZ} / \mathrm{SVZ}}=0.0004\right.$ as determined by a $t$ test $; n=3 ; 9$ brain slices per experiment). $\boldsymbol{K}$, (enpj was specifically knocked down by shCenpj-a and was rescued by the overexpression of Cenpj-td plasmid. GAPDH serving as a loading control. $L$, Quantification of Cenpj protein expression index. Histograms show the mean \pm SD;

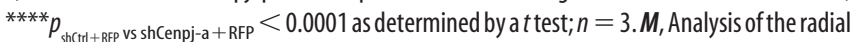
migration of cortices $3 \mathrm{~d}$ after IUE at E13.5. Scale bar, $30 \mu \mathrm{m}$. $\boldsymbol{N}$, Representative time-lapse images of the $R G$ dividing process in the sections of the cerebral cortex electroporated with shCtrl and shCenpj in the wild-type mouse. Arrowheads indicate mother RG cells and asterisks indicate two daughter cells. Scale bar, $20 \mu \mathrm{m}$. $\mathbf{0}$, Ciliogenesis in ARPE19 cells. Cells were treated, fixed at $0 \mathrm{~h}$ or at $24 \mathrm{~h}$ after serum restimulation, and immunostained with anti- $\gamma$ tubulin (red) and anti-acetylated tubulin (gray) antibodies. Enlarged views show the centrosome (right top) and the primary cilia (right bottom). Arrows indicate the cilia. Scale bar, 10 $\mu \mathrm{m}$. $\boldsymbol{P}$, Percentage of ARPE19 cells with primary cilia in GFP-positive cells. Histogram show the means $\pm S D ; p_{0 \mathrm{~h}}=0.7091,{ }^{*} p_{24 \mathrm{~h}}=0.0109$ as determined by a $t$ test; $n>200$ cells. Q, Quantification of the fraction of mitotic cells in prophase/metaphase versus those in anaphase/telophase. Histogram showing the means $\pm S D ; t$ test $; p_{0 \text { h,prophase } / \text { metaphase }}=0.9106$, $p_{0 \mathrm{~h} \text {,anaphase/telophase }}=0.4686,{ }^{* * * *} p_{24 \mathrm{~h} \text {,prophase/metaphase }}<0.0001,{ }^{* * * *} p_{\text {anaphase/telophase }}<$ 0.0001 as determined by a $t$ test; $n>200$ cells.

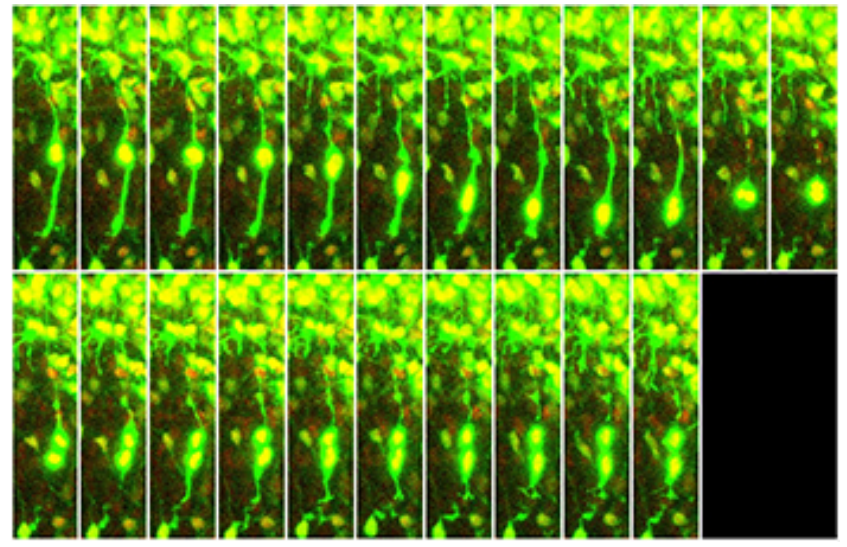

Movie 5. Movie related to Fig. $3 N$ ). Representative time-lapse movie of the RGC dividing process in the sections of the cerebral cortex electroporated with shCtrl in the wild-type mouse.
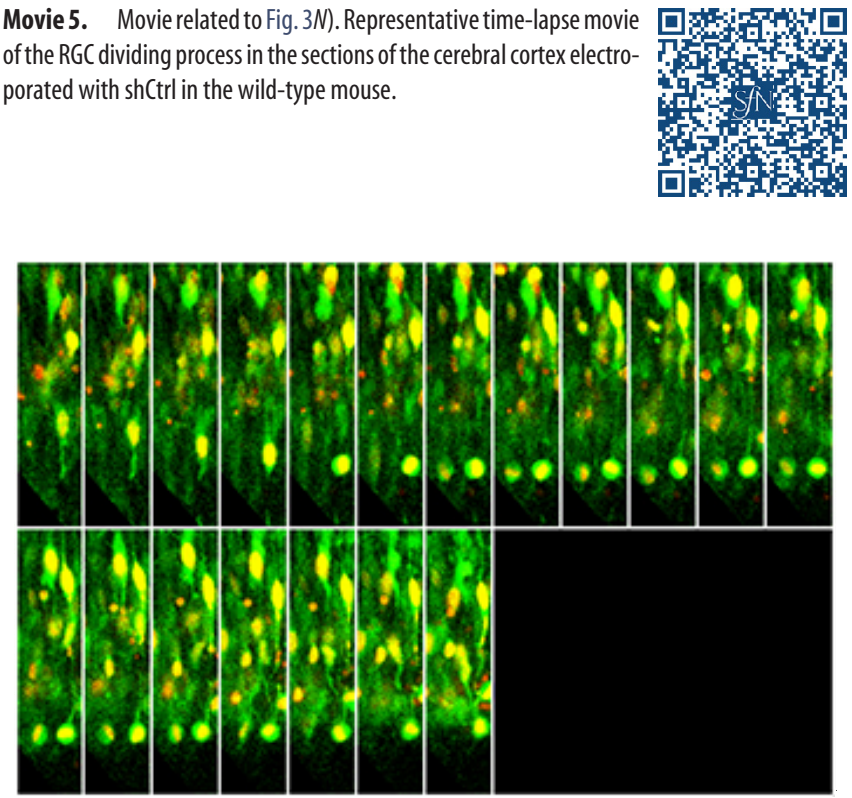

Movie 6. Movie related to Fig. $3 \mathrm{~N}$ showing representative timelapse movie of the RGC dividing process in the sections of the cerebral cortex electroporated with shCenpj in the wild-type mouse.

mally long time following Cenpj depletion (Fig. 3N, Movies 5, 6). To investigate whether Cenpj regulates cilium disassembly to affect the cell cycle, shCenpj-a-transfected ARPE19 cells were starved for cilia induction first and then cultured with serum stimulation for $24 \mathrm{~h}$. The ciliated cells were counted 0 and $24 \mathrm{~h}$ after serum stimulation. Twenty-four hours after serum stimulation, the deletion of Cenpj led to cilia disassembly delay (Fig. $3 O, P)$ and a significant reduction in the proportion of mitotic cells (Fig. 3Q). Together, our results indicate that abnormal cilia disassembly caused by Cenpj depletion influences RG cell divisions.

Because RG cells are mother cells of other types of NPCs involved in cortical development, we next investigated how abnormal cilia caused by Cenpj depletion exert an influence on NPC behavior. NPCs of Cenpj ${ }^{+/+}$and Cenpj ${ }^{\mathrm{CKO}}$ mice at E14.5 were sequentially pulse-chased by using EdU and BrdU, two thymidine analogs, spaced $22 \mathrm{~h}$ apart (Fig. 4A). A reduced number of cells with EdU incorporation in Cenpj ${ }^{\mathrm{CKO}}$ cortices indicated that fewer cells entered S phase at E14.5 (Fig. 4B). Additionally, 
A EdU Brolu Bo

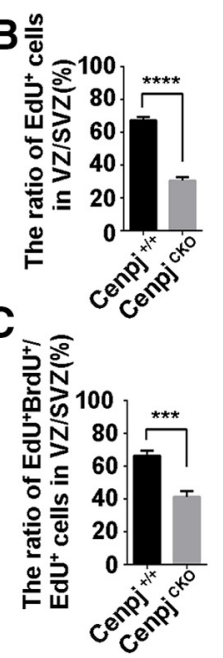

\section{D}

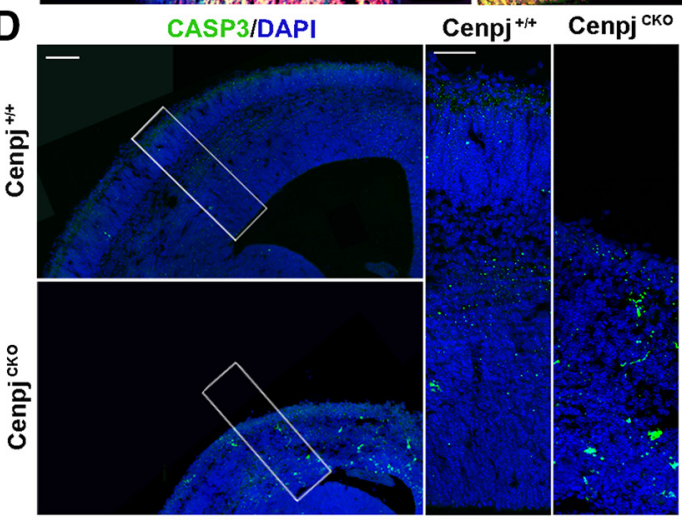

EdU/BrolU/DAPI
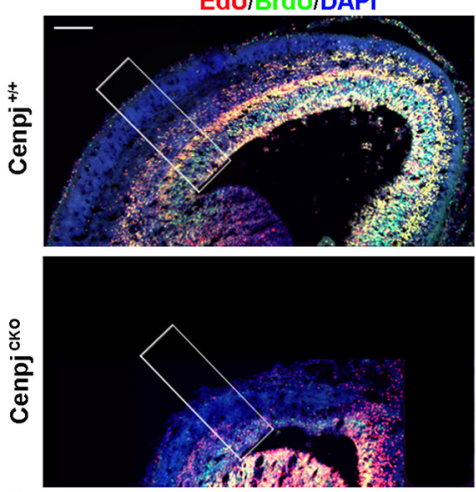

22hr
$\overrightarrow{E 15.5}$ arvest

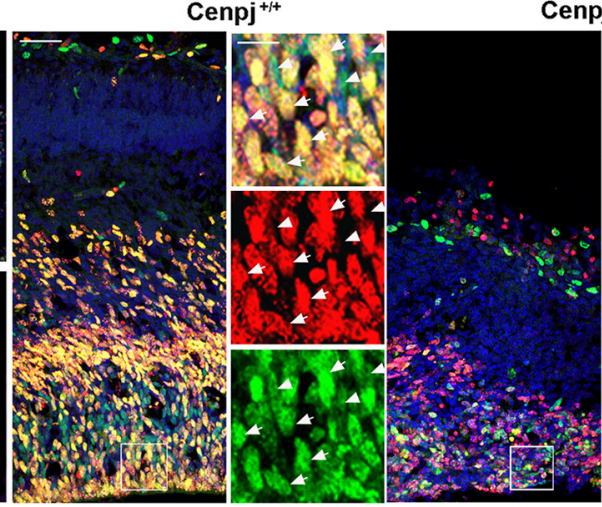

\section{j}

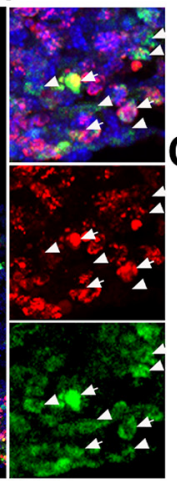

$\mathbf{F}$
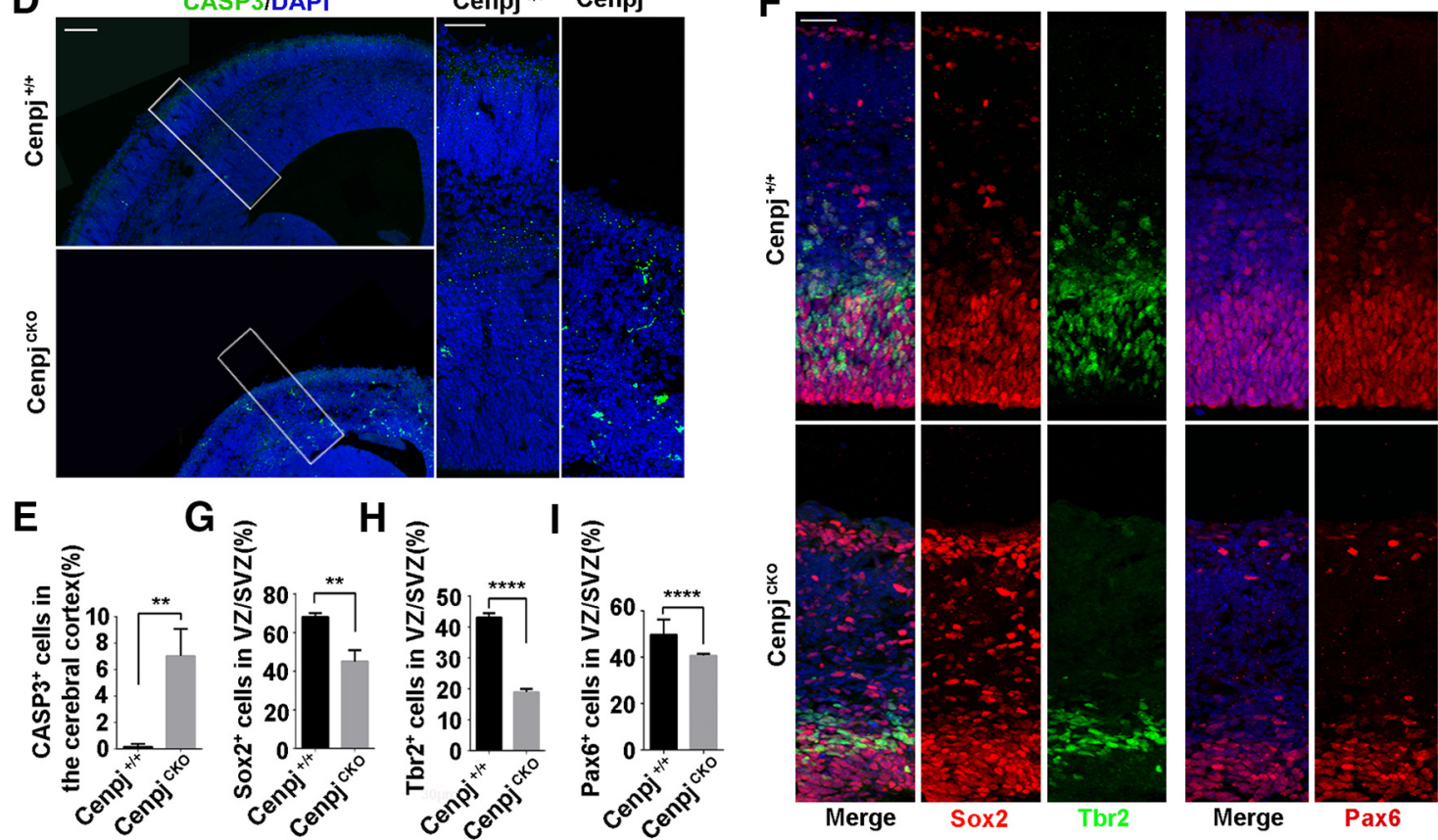

Figure 4. Cenpj deletion in the cortex influences RG cell proliferation during development. $\boldsymbol{A}$, Representative images of E15.5 Cenpj ${ }^{+/+}$and Cenpj ${ }^{\text {CKO }}$ cortices subjected to dual pulse-chase labeling of EdU (red) and BrdU (green). The pulse-chase timing is shown on the top. High-magnification images show the cortical column and NPCs in the VZ/SVZ. Arrowheads indicate BrdU (green)-positive cells and arrows indicate BrdU (green) and EdU (red) double-positive cells. Scale bars, $100 \mu \mathrm{m}$ (top), $10 \mu \mathrm{m}$ (left), and $30 \mu \mathrm{m}$ (right). $B$, Quantification of EdU (red) incorporation in the Cenpj ${ }^{+/+}$and Cenpj ${ }^{\mathrm{CK} 0} \mathrm{VZ/SVZ}$ after $24 \mathrm{~h}$. Histogram shows the mean $\pm \mathrm{SD} ;{ }^{* * * *} p<0.0001$ as determined by $t$ test; $n=3 ; 3$ brain slices per experiment. $C$, Quantification of EdU (red) and BrdU (green) double incorporation in Cenpj ${ }^{+/+}$and Cenpj ${ }^{\text {KK0 }}$ mouse VZ/SVZ. Histogram shows the mean $\pm S D ;{ }^{* * *} p=0.0008$ as determined by $t$ test; $n=3 ; 3$ brain slices per experiment. $\boldsymbol{D}$, Representative images of Caspase3 staining in Cenpj ${ }^{+/+}$and Cenpj ${ }^{\text {CKO }}$ brain at E15.5. Right, Magnifying cortical column. Scale bars, $30 \mu \mathrm{m}$ (left) and $100 \mu \mathrm{m}$ (right). E, Quantification of

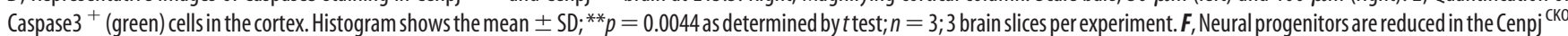
cortex. Representative images of Cenpj ${ }^{+/+}$and Cenpj ${ }^{\text {CK0 }}$ cortices at E15.5, which were stained with antibodies against Sox2 (red), Tbr2 (green), and Pax6 (red). G, Quantification of Sox2 ${ }^{+}$cell ratios in the VZ/SVZ. Histogram shows the mean $\pm S D ;{ }^{* *} p=0.0031$ as determined by $t$ test; $n=3 ; 3$ brain slices per experiment. $\boldsymbol{H}$, Quantification of Tbr2 ${ }^{+}$cell ratios in the VZ/SVZ. Histogram shows the mean $\pm \mathrm{SD} ;{ }^{* * * *} p<0.0001$ as determined by $t$ test; $n=3 ; 3$ brain slices per experiment. I, Quantification of Pax6 ${ }^{+}$cell ratios in the VZ/SVZ. Histogram shows the mean $\pm S D$; ${ }^{* * * *} p<$ 0.0001 as determined by $t$ test; $n=3 ; 3$ brain slices per experiment.

$66.37 \pm 3.13 \%$ Cenpj $^{+/+}$NPCs and $41.32 \pm 3.54 \%$ Cenpj $^{\text {CKO }}$ NPCs in the VZ/SVZ underwent further rounds of cell division in the next $22 \mathrm{~h}$ (Fig. 4C), suggesting that cortical NPCs with Cenpj depletion showed less proliferating potential for consecutive divisions during cortical development. In addition, signals from the apoptosis marker Caspase 3 were observed in the Cenpj ${ }^{\text {CKO }}$ cortex at E15.5 (Fig. 4D,E). We next examined the cortical development and neurogenesis capacities of NPCs upon Cenpj depletion. Compared with the control group, decreased expression of the NPC markers Sox 2 and Pax6 was observed in the Cenpj ${ }^{\mathrm{CKO}}$ cortex compared with the Cenpj ${ }^{+/+}$cortex at E15.5 (Fig. $4 F, G, I$ ). In addition, the population of intermediate progenitor cells identified by Tbr2 was also reduced upon Cenpj depletion (Fig. 4F, $H$ ). Together, these results suggest that depletion of Cenpj reduces NPC proliferation capacities and progenitor number, resulting in cortical thickness reduction during brain development.

Cenpj knock-out reduces adult neural stem cells

The Cenpj ${ }^{\mathrm{CKO}}$ adult mutants also showed a strong microcephalic phenotype in which the telencephalic area estimated by circumference measurement of Cenpj ${ }^{\mathrm{CKO}}$ mice was reduced by $38.0 \%$ in 2-month-old mice (Fig. 5A,B). Nissl staining of Cenpj ${ }^{+/+}$and 
A

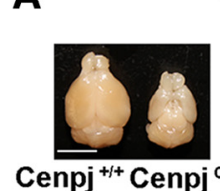

C

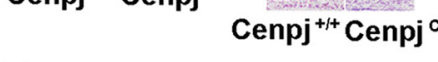

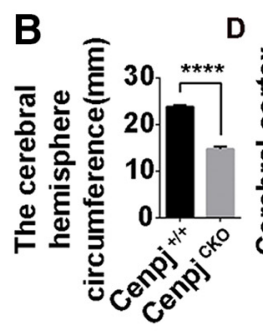
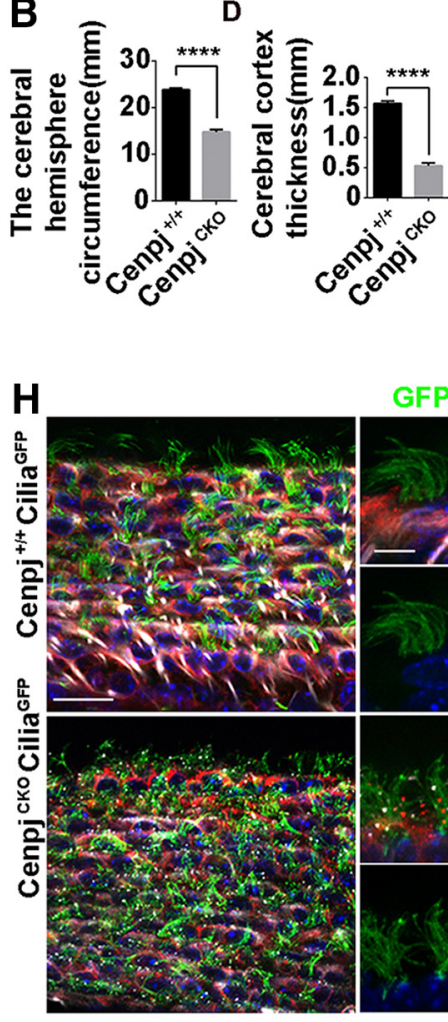

GFP/BCat/GFAP/DAPI

J
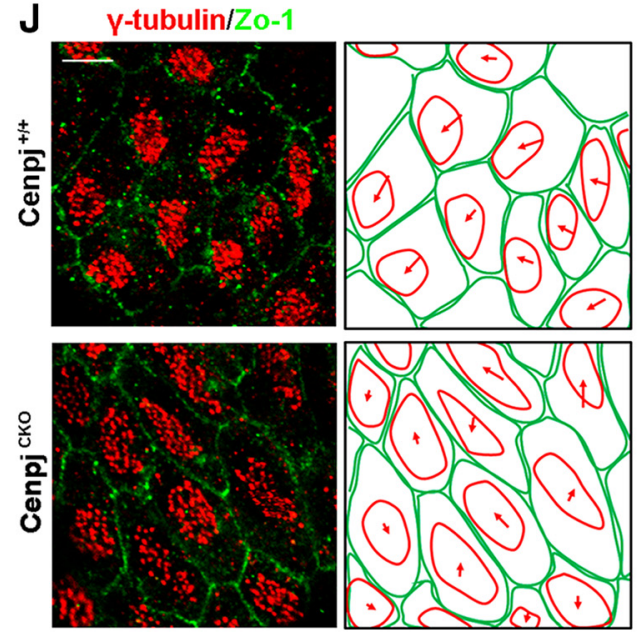

E

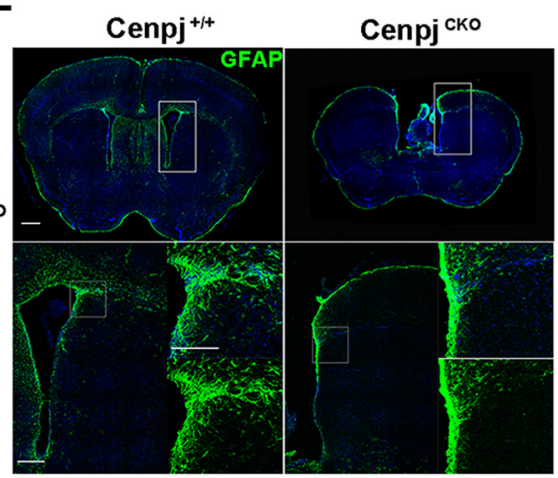

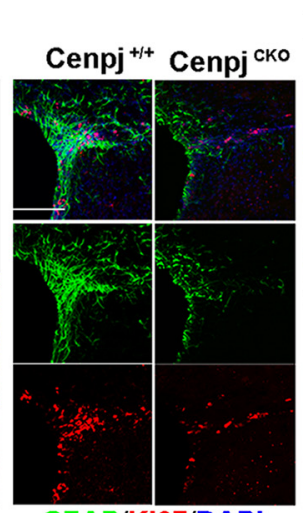

GFAP/KI67/DAPI

$F$
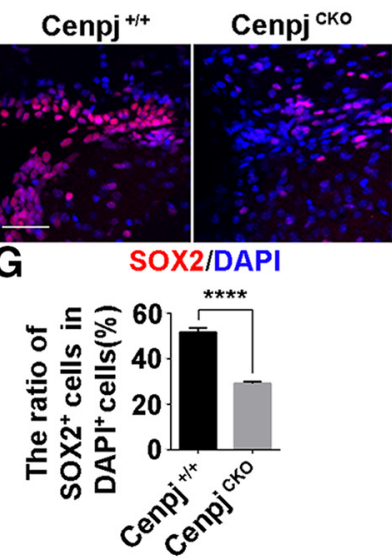

I

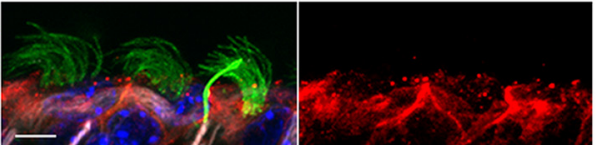

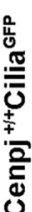

GFAPI

GFPI

$\beta C a t$
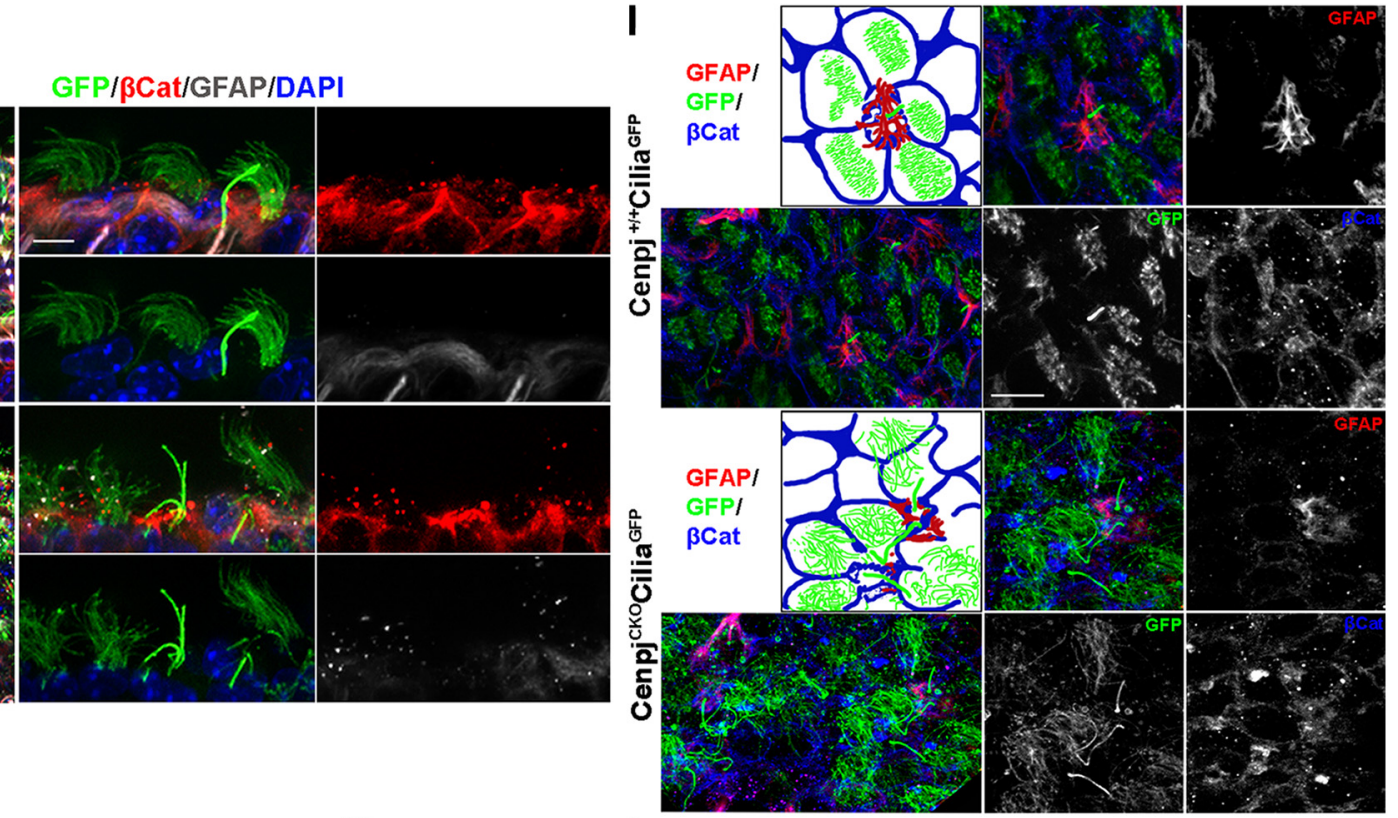

K

$\mathbf{L}$
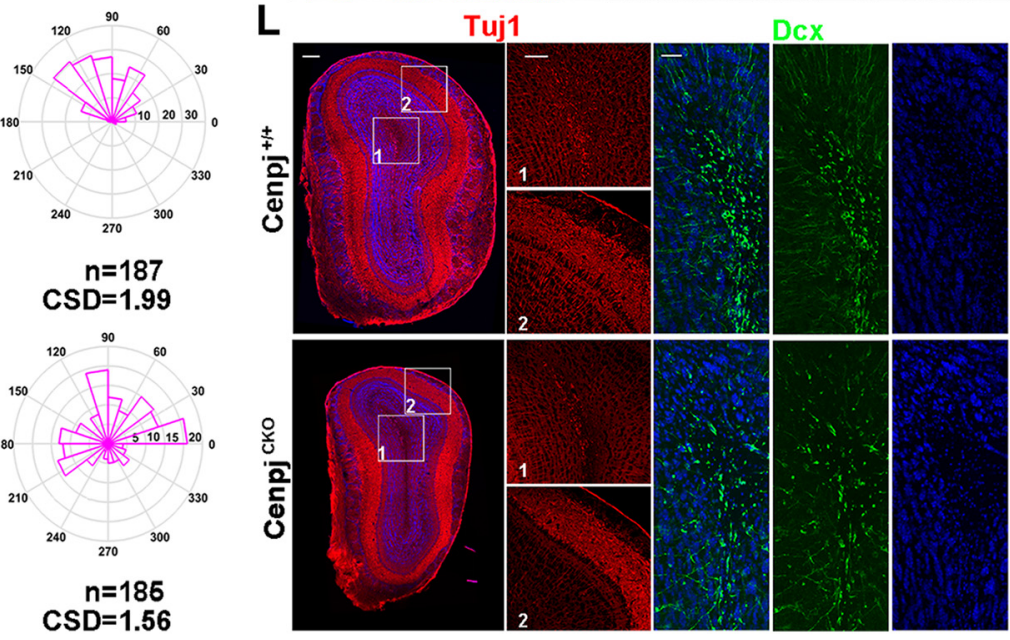

Figure 5. Cenpj knock-out results in defective brains in adult mice. $A$, Representative images of the Cenpj ${ }^{+/+}$and Cenpj ${ }^{\mathrm{CK} 0}$ brain size at adult. Cenpj ${ }^{\mathrm{CK} 0}$ mice show severe microcephaly. Scale bar, $5 \mathrm{~mm}$. B, Quantification of the mouse cerebral hemisphere circumference, Histogram shows the mean \pm SD; ${ }^{* * * *} p<0.0001$ as determined by a $t$ test; $n=3$. C, Representative images of $\mathrm{Cenpj}^{+/+}$and Cenpj ${ }^{\mathrm{CKO}}$ brain cortical column at 2 months by Nissl staining. Right panel shows the magnified images. Scale bar, $100 \mu \mathrm{m}$. D, Histogram of the cortical thickness between the Cenpj $^{+/+}$and Cenpj ${ }^{\mathrm{KK} 0}$ adult cerebral cortex. Data are shown as the means $\pm S D$; ${ }^{* * * *} p<0.0001$ as determined by a $t$ test; $n=3 ; 3$ brains per experiment. $\boldsymbol{E}$, Representative images of Cenpj ${ }^{+/+}$ and Cenpj ${ }^{\mathrm{CK} 0}$ brain slices stained with GFAP (green). Right, Magnified lateral ventricles stained with GFAP (green) and Ki67 (red). Scale bars, $500 \mu \mathrm{m}$ (left top) and $200 \mu \mathrm{m}$ (left bottom and right). $\boldsymbol{F}$, Representative images of Cenpj ${ }^{+/+}$and Cenpj ${ }^{\text {CK0 }}$ brain slices stained with Sox2 (red). Scale bars, $60 \mu \mathrm{m}$. G, Quantification of Sox2 ${ }^{+}$cell ratios in the VZ/SVZ. Histogram shows the mean \pm SD; ${ }^{* * * *} p<0.0001$ as determined by $t$ test $; n=3 ; 3$ brain slices per experiment. $\boldsymbol{H}$, Whole-mount ventricles of Cenpj ${ }^{+/+}$and $\mathrm{Cenpj}{ }^{\mathrm{CKO}}$ brains at P40, which were stained with antibodies against GFAP (gray) and $\beta$-catenin (red) in the Cenpj ${ }^{+/+}$Cilia ${ }^{\text {GFP }}$ and Cenpj ${ }^{\text {CKO }}$ Cilia ${ }^{\text {GFP }}$ mouse VZ/SVZ. Scale bar, $30 \mu \mathrm{m}$ (left) and $10 \mu \mathrm{m}$ (right). $\boldsymbol{I}$, En face views of the adult SVZ pinwheel structure in

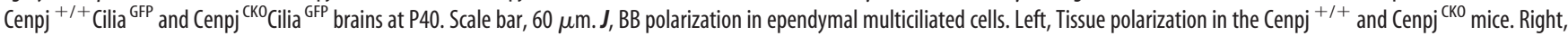
Algorithm for quantification of translational polarity. Scale bar, $10 \mu \mathrm{m}$. $\boldsymbol{K}$, Quantification of BB translational polarity. The angles for BBOVs were calculated and (Figure legend continues.) 

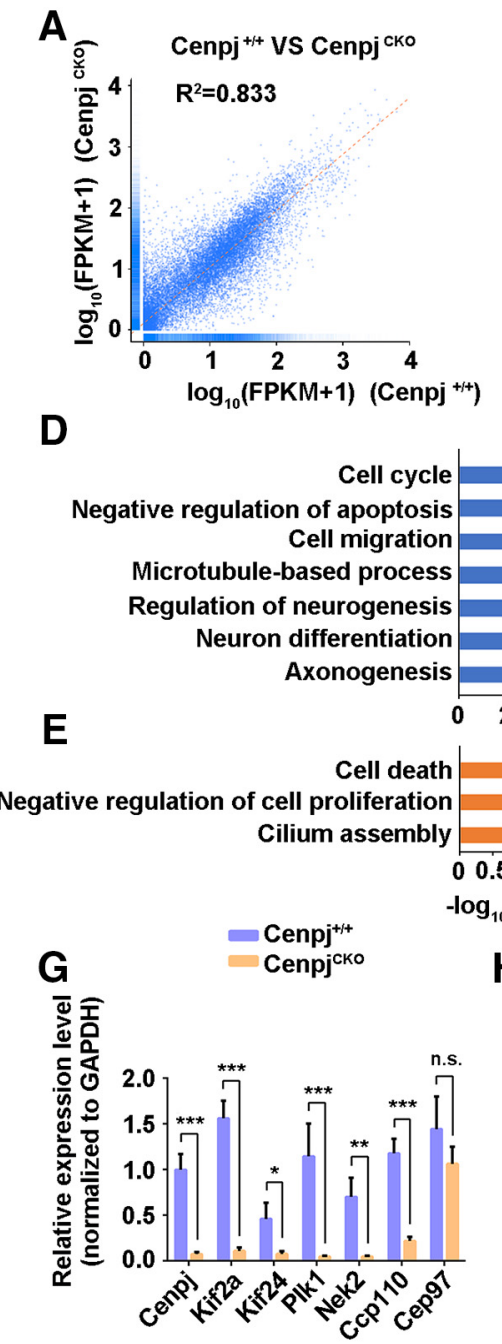

B

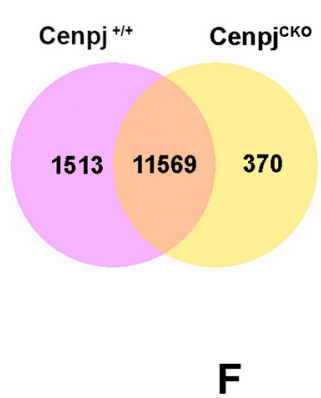

C

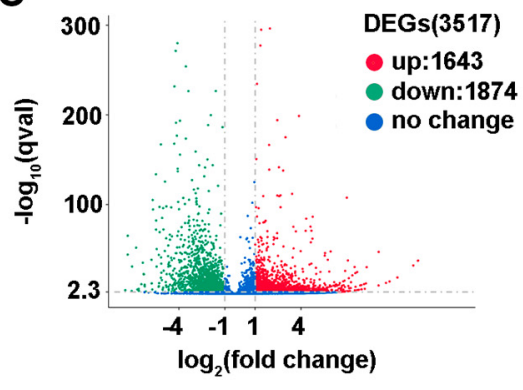

Statistics of Pathway Enrichment

Figure 6. Transcriptome changes in the developing mouse cortex with Cenpj depletion. $\boldsymbol{A}$, RNA-Seq correlation of the gene expression level. $\boldsymbol{B}$, Venn diagrams of the coexpression genes between Cenpj ${ }^{\mathrm{CKO}}$ samples and Cenpj ${ }^{+/+}$samples. C, Scatter plot analysis of transcriptome expression profiles of Cenpj ${ }^{\mathrm{K} 0}$ samples versus Cenpj ${ }^{+/+}$samples at E15.5. Red dots and green dots highlight the significantly upregulated or downregulated expressed genes after (enpj depletion, respectively. Blue dots show no significantly changed genes. $D$, Histogram of the enriched gene ontology (GO) terms of downregulated genes from the pairwise comparison of Cenpj ${ }^{\mathrm{CKO}}$ versus Cenpj ${ }^{+/+}$. The significance of each $\mathrm{GO}$ term was estimated based on corrected $p$-values (corrected $\left.p<0.05\right)$. $\boldsymbol{E}$, Histogram of the enriched $\mathrm{GO}$ terms of upregulated genes from the pairwise comparison of Cenpj ${ }^{\mathrm{CKO}}$ versus Cenpj ${ }^{+/+}$. The significance of each $\mathrm{GO}$ term was estimated based on corrected $p$-values (corrected $p<0.05$ ). $\boldsymbol{F}$, Statistics of enriched KEGG pathway display the varying genes that are involved in many pathways. The size of the point indicates the number of differentially expressed genes in this pathway and the color of the point corresponds to a different $q$-value range. $G, q R T-P C R$-analyzed transcription of genes involved in cilium disassembly. All measured values were normalized to GAPDH gene expression. Histogram shows the mean $\pm S D ;{ }^{* * *} p_{\text {Cenpj }}=0.0008,{ }^{* * *} p_{\text {Kif2a }}=0.0002,{ }^{*} p_{\text {Kif24 }}=0.0220,{ }^{* * * *} p_{\text {Plk } 1}=0.0002,{ }^{* *} p_{\text {Nek2 } 2}=0.0056,{ }^{* * *} p_{\text {Cpp 110 }}=0.0005, p_{\text {Cep } 97}=$ 0.1788 as determined by $t$ test $; n=3 ; 3$ repetitions per experiment. $\boldsymbol{H}$, qRT-PCR-analyzed transcription of genes involved in cilium assembly. All measured values were normalized to GAPDH gene expression. Histogram shows the mean $\pm S D ;{ }^{*} p_{\text {Rab8a }}=0.0484, p_{\text {dff } 2}=0.3714, p_{\text {sct } 1}=0.3873,{ }^{* *} p_{\text {Mks } 1}=0.0038, p_{\text {cep } 89}=0.7596,{ }^{* *} p_{\text {fbf1 }}=0.0060$ as determined by $t$ test; $n=3 ; 3$ repetitions per experiment.

Cenpj $^{\mathrm{CKO}}$ brain slices showed remarkable reductions in the thickness of the cerebral cortex in adult mice upon Cenpj depletion (Fig. $5 C, D$ ). Within the VZ/SVZ of the adult mammalian brain, adult neural stem cells (aNSCs) remain mitotically active and continuously generate olfactory bulb interneurons (Codega et al., 2014). Glial fibrillary acidic protein (GFAP)-positive B1 cells are considered to be aNSCs (Doetsch et al., 1999; García et al., 2004; Mirzadeh et al., 2008). To examine the aNSCs in the

$\leftarrow$

(Figure legend continued.) angular histogram plots are shown (on average 20 cells per field of view were analyzed). $p<0.0001$ as determined by an unpaired Mann-Whitney test. $L$, Representative images of Cenpj ${ }^{+/+}$and Cenpj ${ }^{\mathrm{CK} 0}$ olfactory bulb coronal sections stained with antibodies specific to Tuj1 (red) and Dcx (green). Right panels show the magnified images. Scale bars, $200 \mu \mathrm{m}$ (left) and $100 \mu \mathrm{m}$ (right).
VZ/SVZ, we visualized the aNSCs and niche astrocytes in the $\mathrm{VZ/SVZ}$ by immunostaining for GFAP. GFAP ${ }^{+}$cells were highly enriched on the surface of the lateral ventricle in $\mathrm{Cenpj}^{+/+}$ brains, but only a few $\mathrm{GFAP}^{+}$cells were observed in Cenpj ${ }^{\mathrm{CKO}}$ adult brains (Fig. 5E). Consistent with this observation, dramatically reduced $\mathrm{Ki}^{+}{ }^{+}$cells were also observed in the VZ/SVZ of the Cenpj ${ }^{\mathrm{CKO}}$ brains (Fig. $5 E$ ). Furthermore, there were fewer SOX2 ${ }^{+}$type $\mathrm{C}$ cells in the VZ/SVZ of the Cenpj ${ }^{\mathrm{CKO}}$ brains (Fig. $5 F, G)$. The VZ/SVZ in the adult mouse brain is a highly organized microenvironment composed of aNSCs and multiciliated ependymal cells, which are responsible for the niche cytoarchitecture and the regulation of the self-renewal and differentiation potential of aNSCs (Lim et al., 2000; Kuo et al., 2006; RamírezCastillejo et al., 2006; Gajera et al., 2010; Paez-Gonzalez et al., 2011). En face and side views of the ventricle were labeled by 
A

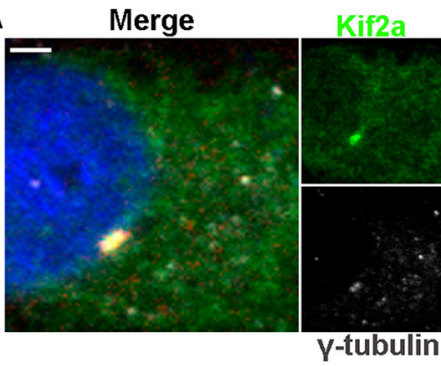

E

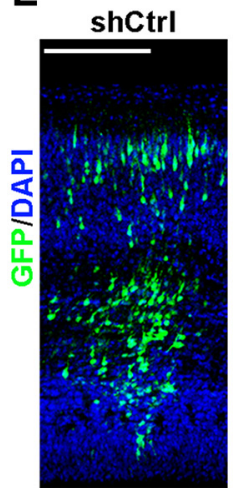

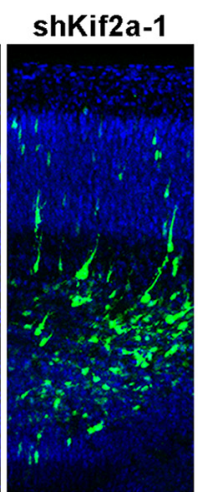

Cenpj

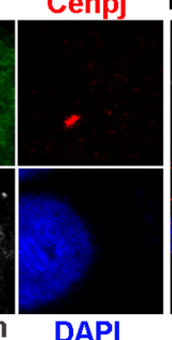

B

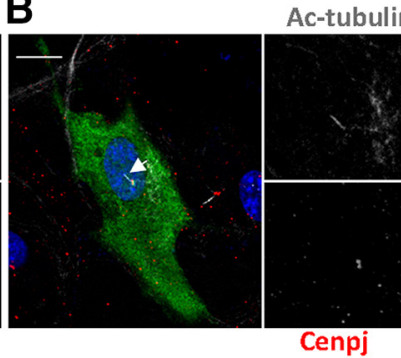

C

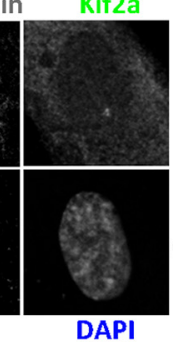

\section{GA}

G

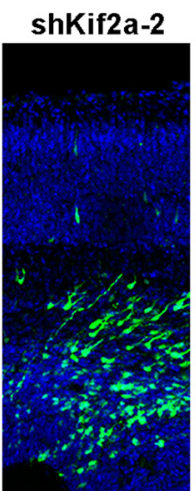

F

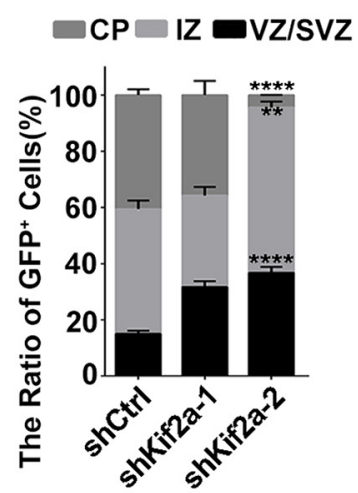

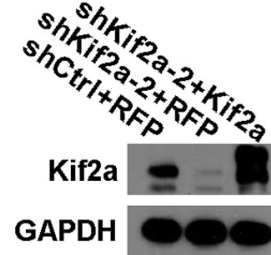

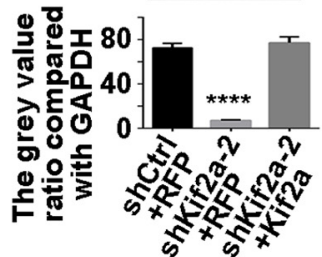

D

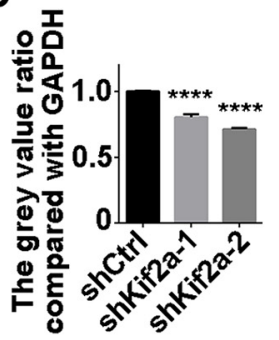

Figure 7. Cenpj regulates cortical development via Kif2a. A, ARPE19 cells were Immunostained with anti- $\gamma$-tubulin (gray) and anti-Cenpj (red) antibodies. Scale bars, $2 \mu \mathrm{m} . \boldsymbol{B}$, ARPE19 cells were transfected with GFP-Kif2a and immunostained with anti-acetylated tubulin (gray) and anti-Cenpj (red) antibodies. Arrow indicates the cilium. Scale bar, $10 \mu \mathrm{m}$. $\boldsymbol{C}$, Overexpressed Kif2a was efficiently knocked down by Kif2a shRNAs. GAPDH serving as a loading control. $\boldsymbol{D}$, Quantification of Kif2a knock-down efficiency by shRNAs. Histograms show the mean \pm SD; $*{ }^{* * *} p_{\text {shctrl }}$ v shkifza-1 $<$ $0.0001,{ }^{* * * *} p_{\text {shctrl vs shKifza-2 }}<0.0001$ as determined by a $t$ test $; n=3$. E, Analysis of the radial migration of cortices $3 \mathrm{~d}$ after IUE at E13.5 with control shRNA, shKif2a-1, and shKif2a-2. Scale bar, $30 \mu \mathrm{m}$. $\boldsymbol{F}$, Quantification of the neurogenesis after silencing Kif2a by measuring the percentages of GFP ${ }^{+}$cells that have reached the different zones of the cortex $3 \mathrm{~d}$ after electroporation. Histograms show the mean $\pm \mathrm{SD}$; shCtrl vs shKif2a-2 $\left({ }^{* * *} p_{\mathrm{CP}}<0.0001,{ }^{* *} p_{\mathrm{IZ}}=0.0025,{ }^{* * * *} p_{\mathrm{VZ} / \mathrm{sVZ}}<0.0001\right.$ as determined by $t$ test; $n=3 ; 9$ brain slices per experiment). G, Kif2a are specifically knocked down by shKif2a-2 and rescued by overexpression of Kif2a-td plasmid. GAPDH served as a loading control. $\boldsymbol{H}$, Quantification of Kif2a protein expression index. Histograms show the mean $\pm S D ; * * * *{ }_{\text {shtrrl }+ \text { RFP vs shkif2a-2+RFP }}<0.0001$ as determined by a $t$ test; $n=3$. I, Analysis of the radial migration of cortices $3 \mathrm{~d}$ after IUE at E13.5. Scale bar, $30 \mu \mathrm{m}$.

immunofluorescence staining for $\beta$-catenin, which is a marker of ependymal cell membranes, and GFAP, which is a marker of B1 cells, in the Cenpj ${ }^{+/+} \mathrm{Cilia}^{\mathrm{GFP}}$ and Cenpj ${ }^{\mathrm{CKO}} \mathrm{Cilia}{ }^{\mathrm{GFP}}$ brains at postnatal day $40(\mathrm{P} 40)$ (Fig. $5 \mathrm{H}, \mathrm{I})$. $\mathrm{GFAP}^{+} \mathrm{B} 1$ cells were reduced in Cenpj ${ }^{\mathrm{CKO}}$ brains and the orientation of the motile cilia on the ependymal cells was disarrayed in Cenpj ${ }^{\mathrm{CKO}}$ brains (Fig. $5 \mathrm{H}, \mathrm{I}$ ). We also found that the lengths of the primary cilia on the B1 cells in Cenpj ${ }^{\mathrm{CKO}}$ brains were increased compared with those in Cenpj $^{+/+}$brains (Fig. $5 H, I$ ). Cilia BBs migrate toward the anterior side of a cell, creating so-called translational polarity, which is critical for the coordinated movement of cilia (Mirzadeh et al., 2010; Wallingford, 2010). We further addressed the BB patches by confocal microscopy using the $\mathrm{BB}$ marker $\gamma$-tubulin and the ependymal cell membrane marker Zo-1 to reveal the structure of the Cenpj ${ }^{+/+}$and Cenpj ${ }^{\mathrm{CKO}}$ VZ/SVZ. BB patches are essential for the directional beating of motile cilia. $\mathrm{BB}$ patches of Cenpj ${ }^{\mathrm{CKO}}$ adult mice often migrated in a different direction from the neighboring cells, whereas the majority of Cenpj ${ }^{+/+} \mathrm{BB}$ patches were in the same direction (Fig. $5 \mathrm{~J}, K$ ). Moreover, aNSCs continuously generate olfactory bulb interneurons (Codega et al., 2014). Neuron-specific class III $\beta$-tubulin (Tuj1) was expressed in immature postmitotic neurons. As expected, Tuj ${ }^{+}$cells were reduced in the olfactory bulb of Cenpj ${ }^{\mathrm{CKO}}$ adult mice compared with those in the olfactory bulb of Cenpj ${ }^{+/+}$adult mice, especially in the granule cell layer. Moreover, decreased $\mathrm{Dcx}^{+}$cells were also observed in the granule cell layer (Fig. $5 L$ ). Cenpj depletion not only affects aNSC proliferation and adult neurogenesis, but also influences the primary cilia of B1 cells and motile cilia of the ependymal cells, showing long cilia with disorganized arrangements.

\section{Cenpj regulates cilia disassembly and cortical development} through Kif2a

To understand the molecular mechanism underlying how Cenpj depletion leads to cilium abnormality and microcephaly, we performed RNA-Seq to analyze the transcriptome changes in Cenpjdepleted cortices at E15.5. An RNA-Seq correlation test showed the high similarity of the expression patterns between Cenpj ${ }^{+/+}$ and Cenpj ${ }^{\mathrm{CKO}}$ samples (Fig. 6A): 11,569 genes were expressed in both Cenpj $^{\mathrm{CKO}}$ and Cenpj ${ }^{+/+}$samples and 1513 genes and 370 genes were expressed in only Cenpj ${ }^{+/+}$or Cenpj $^{\text {CKO }}$ samples, respectively (Fig. 6B). By comparing gene expression levels in Cenpj $^{+/+}$and Cenpj ${ }^{\mathrm{CKO}}$ samples, we found 3517 differentially expressed genes (1643 upregulated and 1874 downregulated) (Fig. $6 C, \log _{2}$ (fold change) $>1, q$-value $<0.005$ ). Gene ontology term analysis of the downregulated genes in E15.5 Cenpj ${ }^{\mathrm{CKO}}$ samples showed a significant enrichment of terms related to cell cycle, cell migration, neurogenesis, neuronal differentiation, and axonogenesis, whereas the upregulated genes were enriched in cell death and cilium assembly (Fig. 6D,E). KEGG signaling pathway analysis revealed that the differentially expressed genes are predicted to be involved in Wnt, MAPK, Hippo, AMPK, and Notch, as well as other signaling pathways (Fig. $6 F$ ). With Cenpj depletion, we found that a number of genes involved in cilium disassembly were downregulated in the developing mouse cortex at E15.5, including Kif2a, Kif24, Plk1, Nek2, and Ccp110 (Fig. 6G), whereas some cilium assembly genes, such as Rab8a and Mks1 (Fig. $6 H$ ), were upregulated, which is consistent with the RNASeq data.

Cilium assembly and disassembly are tightly controlled by Wnt signaling pathways (Liang et al., 2016; Sánchez and Dyn- 


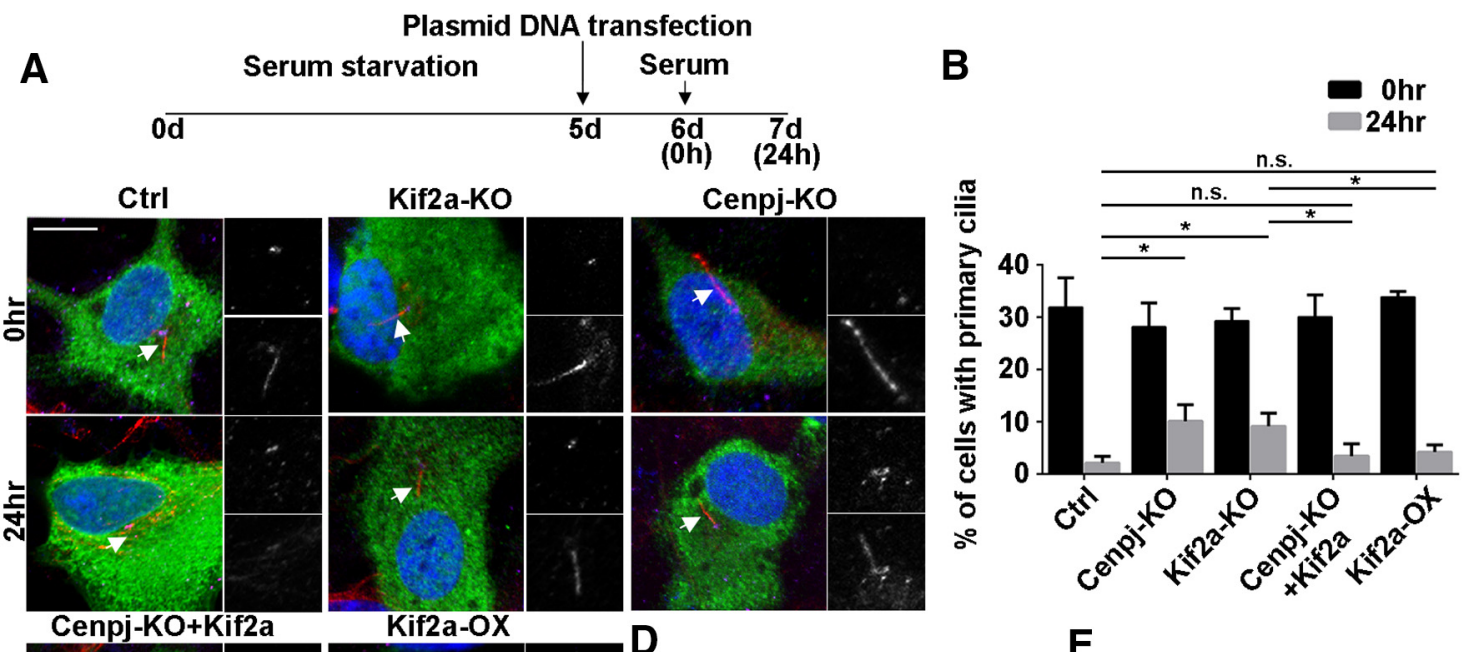

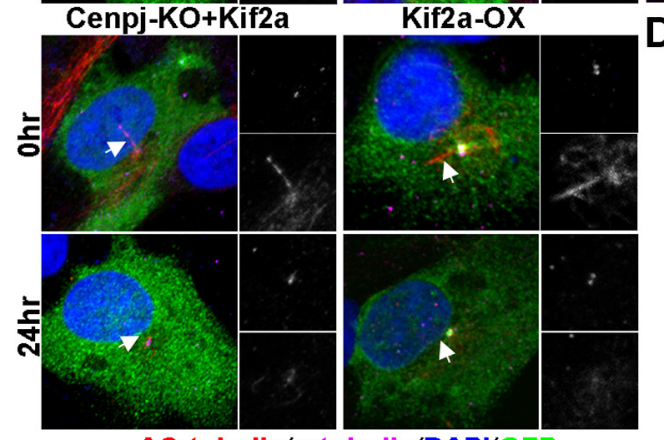

AC-tubulin/Y-tubulin/DAPI/GFP

C

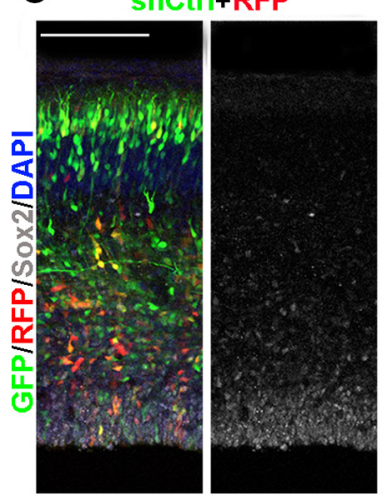

shCenpj+RFP

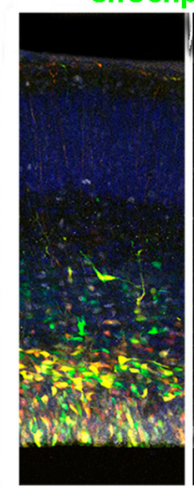

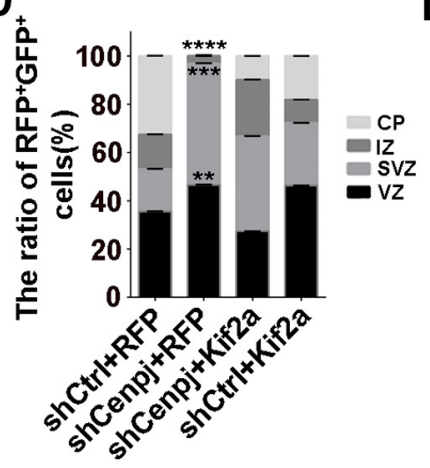

shCenpj+Kif2a

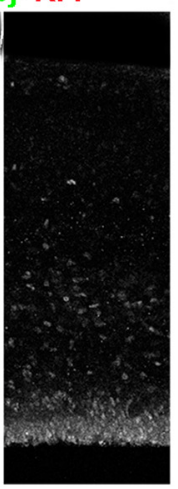

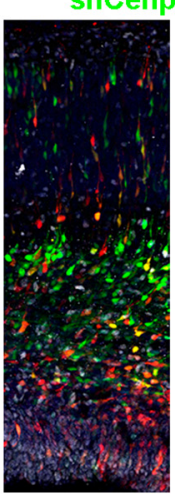

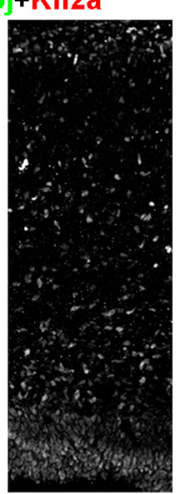

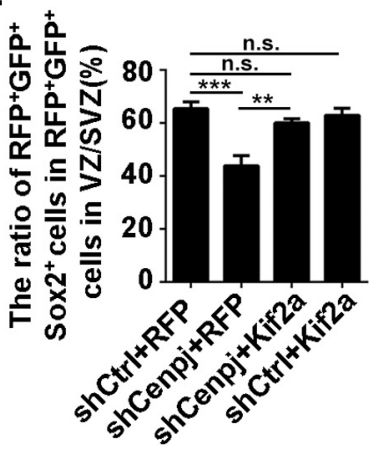

shCtrl+Kif2a

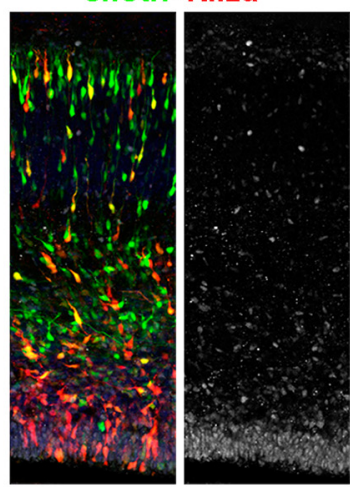

Figure 8. Kif2a rescues the phenotype caused by Cenpj deletion. $A$, Ciliogenesis in ARPE19 cells. Cells were treated, fixed at $0 \mathrm{~h}$ or at $24 \mathrm{~h}$ after serum restimulation, and immunostained with anti- $\gamma$-tubulin (purple) and anti-acetylated tubulin (red) antibodies. Enlarged views show the centrosome (right top) and primary cilia (right bottom). Arrows indicate the primary cilia. Scale bar,

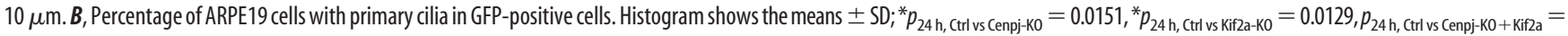

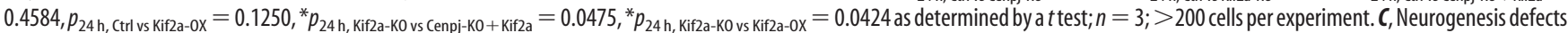
caused by Cenpj depletion were rescued by Kif2a expression. Confocal images of cortices $3 \mathrm{~d}$ after IUE at E13.5. shRNA-GFP (green), Kif2a-RFP (red), Sox2 (gray). Scale bar, $30 \mu \mathrm{mm}$. $D$, Quantification of the migration of neurons by measuring the percentages of GFP ${ }^{+}$and RFP ${ }^{+}$cells that reached the different zones of the cortex $3 \mathrm{~d}$ after electroporation. Histogram shows the means \pm SD; shCtrl+RFP vs shCenpj+RFP $\left({ }^{* * * *} p_{\text {CP }}<0.0001,{ }^{* * *} p_{1 Z}<0.0001,{ }^{* * * *} p_{\text {SVZ }}<0.0001,{ }^{* *} p_{\mathrm{VZ}}=0.0039\right.$ as determined by a $t$ test; $n=3 ; 9$ brain slices per experiment). $E$, Quantification of the neural stem cell number was measured by counting the percentage of GFP ${ }^{+} \mathrm{RFP}^{+} \mathrm{Sox2}{ }^{+}$cells in the VZ/SVZ. Histogram shows the means $\pm \mathrm{SD}$; ${ }^{* * *} p_{\text {shctrl }+ \text { RFP vs shcenpj }+\mathrm{RFP}}=$ $0.0008, p_{\text {shCtrl }+ \text { RFP vs shCenpj }+ \text { Kifza }}=0.5416, p_{\text {shCtrl }+ \text { RFP vs shctrl }+ \text { Kif2a }}=0.8628,{ }^{* *} p_{\text {shCenpj }+ \text { RFP vs shCenpj }+ \text { Kif2a }}=0.0011, t$ test $; n=3 ; 9$ brain slices per experiment.

lacht, 2016). Given that Kif2a is a component of the Wnt pathway and plays a role in MT depolymerizing and disassembly of primary cilia (Trinczek et al., 2004; Miyamoto et al., 2015) and that Kif2a transcription was reduced upon Cenpj depletion, we hypothesized that Cenpj may regulate cilia disassembly through the PLK1-Kif2a signaling pathway. To test this hypothesis, we transfected GFP-Kif2a into ARPE19 cells and immunostained with $\gamma$-tubulin and anti-Cenpj antibodies. Kif2a was colocalized with Cenpj and $\gamma$-tubulin in centrosomes (Fig. 7A). This colocalization of Kif2a and Cenpj also existed when the mother centrioles served as the BBs for the primary cilia (Fig. $7 B$ ). To determine whether Cenpj regulates cilium disassembly via Kif2a, we first evaluated whether knock-down of Kif2a alone by shRNA disrupted neurogenesis in vivo. Given that the shRNAs were highly efficient in knocking down Kif2a (Fig. 7C,D), these shRNA constructs were electroporated into the mouse cortex via IUE at E13.5 and the brains were examined $3 \mathrm{~d}$ later (E16.5). Similar to Cenpj knock-down, Kif2a depletion via two different shRNA plasmids also impaired neurogenesis (Fig. $7 E, F$ ). The neurogenesis defects were rescued by expression of the Kif2a-td plasmid (Fig. 7G-I). 

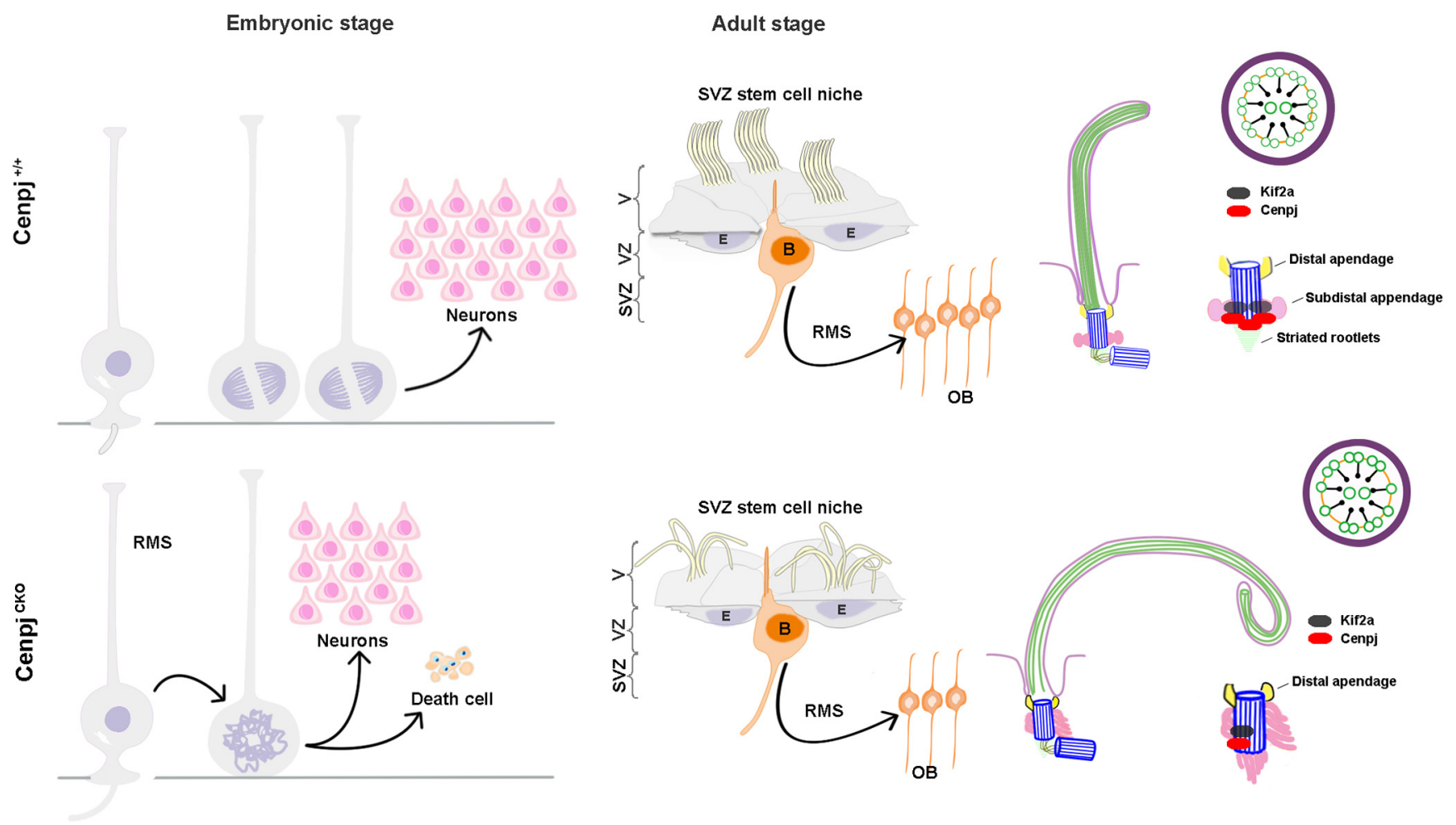

Figure 9. Model of Cenpj function in neurogenesis in the developing neocortex. Depletion of Cenpj causes long primary cilia and abnormal appendages of RG cells at the embryonic stage, resulting in NPC cycle blockage and cell death. At the adult stage, depletion of Cenpj contributes to long thin motile cilia with curly tips on the ependymal cells and long primary cilia on the B cells. Abnormal arrangement of the microtubule doublets and disorganized cilia appendages were also observed. We show that Cenpj regulates cilia disassembly and neurogenesis through Kif2a.

To determine whether Kif2a is a downstream effector of Cenpj, thus regulating cilium disassembly, we cotransfected serum-starved ARPE19 cells with control shRNA shKif2a, shCenpj, a combination of shCenpj and GFP-Kif2a, or GFPKif2a alone and then cultured the cells with serum stimulation for $24 \mathrm{~h}$. To evaluate the effect on cilia disassembly, we counted the ciliated cells 0 and $24 \mathrm{~h}$ after serum stimulation. We found that deletion of either Cenpj or Kif2a led to a delay in cilia disassembly (Fig. $8 A, B$ ). Additionally, the cilia disassembly caused by Cenpj depletion was rescued by expressing Kif2a, whereas overexpression of Kif2a alone had no effect on cilia disassembly (Fig. 8A,B). We next investigated whether Kif2a functions as a downstream effector of Cenpj in regulating cortical neurogenesis. We observed that more neurons migrated to the cortical plate after Kif2a expression in the shCenpj cortex (Fig. $8 C, D$ ). Moreover, Sox $2^{+}$cells among $\mathrm{GFP}^{+}$Cenpj-knock-down cells were greatly reduced compared with control samples, consistent with the finding that Cenpj depletion reduced the NPC pool in the developing mouse cortex. This Sox ${ }^{+}$NPC reduction was rescued by expressing Kif2a (Fig. 8C,E). Together, our results indicate that Kif2a may be a downstream effector facilitating Cenpj to regulate cilium disassembly and is responsible for NPC generation and cortical development.

\section{Discussion}

In this study, we have illustrated the role of Cenpj in regulating cilia disassembly in mouse NPCs. We found that depletion of Cenpj caused long primary cilia of RG cells at the embryonic stage and long curl motile cilia on ependymal cells at the adult stage. We also demonstrated that Kif2a contributes to Cenpj-controlled primary cilia disassembly, which may be responsible for NPC cycle delay and neurogenesis (Fig. 9).
Microcephaly mutations happen most often in centrosomal proteins. Mutations in Nde1, Cdk5rap2, Magoh, and Cenpj induce microcephaly through a combination of loss of progenitor self-renewal, premature differentiation, and progenitor apoptosis (Pawlisz et al., 2008; Lizarraga et al., 2010; Silver et al., 2010; McIntyre et al., 2012; Houlihan and Feng, 2014). The apoptosis induced by Nde1 and Cenpj mutations is p53 dependent (Bazzi and Anderson, 2014; Houlihan and Feng, 2014). Overexpressing the centriole duplication protein PLK4 with a microcephaly phenotype is caused by aneuploidy-linked cell death (Marthiens et al., 2013). Aspm mutants exhibit mild microcephaly resulting from cell death associated with genomic instability and DNA damage (Fujimori et al., 2014; Williams et al., 2015), whereas Wdr62 mutant mice have a modestly reduced brain size resulting from premature cell-cycle exit, which causes defects in the mitotic progression of embryonic neural progenitors (Bogoyevitch et al., 2012; Chen et al., 2014). Centrosomes are templates for ciliogenesis, so it is conceivable that altered ciliogenesis could underlie the pathophysiology of microcephaly to some extent. Recent studies have shown that the proper timing of cilium disassembly mediated by Nde1 and TcTex1 is critically regulated during the cell cycle (Kim et al., 2011; Li et al., 2011; Maskey et al., 2015) and that mutations in Ndel cause microcephaly. There have been some studies identifying the role of centrosome proteins in cilium in regulating neural stem cells during cortical development (Breunig et al., 2008; Han et al., 2008; Willaredt et al., 2008; Wilson et al., 2012; Hu et al., 2014). Our results added more information, supporting the idea that ciliogenesis controlled by Cenpj is required for regulation of NPC cycles, in addition to its function in cell apoptosis in microcephaly disorders (Gabriel et al., 2016). 
Cenpj is a conserved centrosomal protein and is crucial for centrosome biogenesis and many other important processes in addition to the cilia-related function. Cenpj regulates centriole duplication (Gönczy, 2012; Firat-Karalar and Stearns, 2014; Hirono, 2014) and elongation (Schmidt et al., 2009). Cenpj ${ }^{\text {CKO }}$ mice show neurogenesis defects and microcephaly due to a loss of centrioles, but spindles can still be formed (Insolera et al., 2014). Cenpj also plays an essential role as a scaffold for cytoplasmic PCM complexes and contributes to the recruitment of PCM to centrioles (Zheng et al., 2014). Many studies have shown that Cenpj depletion causes defects in the size of centrosomes at the spindle poles (Kirkham et al., 2003; Cho et al., 2006; Dzhindzhev et al., 2010; Gopalakrishnan et al., 2011; Zheng et al., 2014; Conduit et al., 2015). Therefore, Cenpj mutations or deletions lead to increase of the cells with monopolar, abnormal bipolar, and multipolar spindles, resulting in mitosis arrest and apoptosis (Cho et al., 2006; Kitagawa et al., 2011). In addition, cells with abnormal asymmetric bipolar spindles exhibit spindle orientation defects leading to mitotic cleavage randomization (Kitagawa et al., 2011). The disassembly of cilia affects the natural structure of centrosome and possibly impairs microtubule nucleation capacity, which could also result in spindle disorganization and mispositioning. Therefore, our results suggest that neurogenesis failure could be a correlative outcome of the defects in centrosome biogenesis and ciliary disassembly in mice.

From the RNA-Seq data, we note that genes in the Wnt signaling pathway, which is important for regulating gene transcription and maintaining microtubule stabilization, were downregulated upon Cenpj depletion, suggesting that related abnormal cilium morphology and dynamics might be regulated via Wnt signals. Indeed, a number of Wnt signaling components have been observed in the axoneme and at the BBs and the noncanonical Wnt signaling pathway has been linked to ciliary assembly (Wallingford and Mitchell, 2011; Lienkamp et al., 2012) and disassembly (Lee et al., 2012). Recent studies, however, have revealed that a mitotic kinase Polo-like kinase 1 (Plk1) plays a pivotal role in primary cilia disassembly (Lee et al., 2012; SeegerNukpezah et al., 2012; Wang et al., 2013). In response to the ligand Wnt5a, Plk1 forms a complex with Dvl2. The Dvl2-Plk1 complex is required to stabilize and inhibit HEF1 degradation, leading to Aurora A activation, which phosphorylates and activates HDAC6 to increase axonemal microtubule instability, leading to ciliary disassembly (Lee et al., 2012). PLK1 also phosphorylates histone deacetylase 6 (HDAC6) to promote tubulin deacetylation and to destabilize the axonemal MTs of primary cilia (Wang et al., 2013). Moreover, PLK1 promotes primary cilia disassembly through the KIF2A pathway via its MT-depolymerizing activity in a growth-signal-dependent manner (Miyamoto et al., 2015). Our data support the model that Cenpj-regulated cilia disassembly is due to PLK1-KIF2A pathway dysfunction. Kif2a belongs to the kinesin-13 gene family. Unlike conventional kinesin motor proteins involved in intracellular transport, kinesin-13 proteins do not walk along MTs, but have the unique activity of ATP-dependent MT depolymerization (Walczak et al., 2013). Cenpj may recruit Kif2a at the subdistal appendages, which depolymerize centrosomal (cytoplasmic) MT to arrest transport of materials such as tubulin into cilia (Bhogaraju et al., 2013). Further studies are required to clarify how the MT-depolymerizing activity of Kif2a is transmitted to primary cilia disassembly.

In most mammals, the VZ/SVZ continues to produce neurons and glial cells throughout adulthood. Our results indicate a defect in the postnatal stem cell niche of the Cenpj ${ }^{\mathrm{CKO}}$ adult mice. The
VZ/SVZ adult neurogenic niche is established at postnatal stages from a subpopulation of embryonic RG cells. RG cells constitute a heterogeneous population of cells that give rise to both type-B1 aNSCs and multiciliated ependymal cells in addition to neurons and glial cells (Guérout et al., 2014). Depletion of Cenpj in RG cells results in abnormal ciliary structures, such as disorganized $\mathrm{BB}$ structures, long cilia, and misarranged microtubule structures. Similarly, aNSCs and ependymal cells in the SVZ of the Cenpj ${ }^{\mathrm{CKO}}$ adult mice also show long cilia and disordered appendages. Depletion of Cenpj not only results in a decrease in embryonic neurogenesis but also influences adult neurogenesis. Ependymal cells and CSF are integral components of the adult VZ/SVZ niche (Lehtinen et al., 2011) and disruption of motile cilia in ependymal cells is likely to indirectly affect VZ/SVZ progenitors. Because Cenpj depletion also affects the structure of motile cilia in ependymal cells and therefore CSF flow, new approaches to selectively ablate cilia in VZ/SVZ B1 progenitors, but not ependymal cells, are required to understand the role of primary cilia in these periventricular aNSCs.

The primary cilia at the embryonic stage and the adult motile cilia showed similar phenotypes following Cenpj depletion and motile cilia are terminally differentiated, indicating that there is still an intrinsic pathway controlled by Cenpj interrupted in all cilia independent of the cell cycle. Cenpj is required for centrosome duplication and possesses the ability to destabilize, not only cytoplasmic microtubules, but also cilium disassembly (Hung et al., 2004; Tang et al., 2009). A lack of the Cenpj CC5 domain causes long cilia (Gabriel et al., 2016), whereas the N-terminal tubulin-binding domain is responsible for centriole and cilium elongation (Wu and Tang, 2012). We observed that, in addition to cilia length regulation, Cenpj plays roles in controlling the cilium axoneme and $\mathrm{BB}$ structure. The bulging and curly tip phenotype seen following Cenpj depletion may be the result of aberrant arrangement of the microtubule doublets. Individuals with microcephaly have characteristic facies, skeletal dysplasia, and abnormal dentition and have an increased risk of cerebrovascular disease; insulin resistance, severe neonatal cholestasis, and histological dysplasia of the kidneys have also been found in microcephaly patients (Berger et al., 1998; Bober and Jackson, 2017). We speculate that the cilia abnormalities in these organs could be one of the causes of these defects. Our mouse model with Cenpj deletion provides an ideal model in which to test this possibility in preclinical studies.

\section{References}

Al-Dosari MS, Shaheen R, Colak D, Alkuraya FS (2010) Novel CENPJ mutation causes seckel syndrome. J Med Genet 47:411-414.

Basten SG, Giles RH (2013) Functional aspects of primary cilia in signaling, cell cycle and tumorigenesis. Cilia 2:6.

Basto R, Lau J, Vinogradova T, Gardiol A, Woods CG, Khodjakov A, Raff JW (2006) Flies without centrioles. Cell 125:1375-1386.

Bazzi H, Anderson KV (2014) Acentriolar mitosis activates a p53dependent apoptosis pathway in the mouse embryo. Proc Natl Acad Sci U S A 111:E1491-E1500.

Berger A, Haschke N, Kohlhauser C, Amman G, Unterberger U, Weninger M (1998) Neonatal cholestasis and focal medullary dysplasia of the kidneys in a case of microcephalic osteodysplastic primordial dwarfism. J Med Genet 35:61-64.

Bhogaraju S, Cajanek L, Fort C, Blisnick T, Weber K, Taschner M, Mizuno N, Lamla S, Bastin P, Nigg EA, Lorentzen E (2013) Molecular basis of tubulin transport within the cilium by IFT74 and IFT81. Science 341:10091012.

Bober MB, Jackson AP (2017) Microcephalic osteodysplastic primordial dwarfism, type II: a clinical review. Curr Osteoporos Rep 15:61-69.

Bogoyevitch MA, Yeap YY, Qu Z, Ngoei KR, Yip YY, Zhao TT, Heng JI, Ng DC (2012) WD40-repeat protein 62 is a JNK-phosphorylated spindle 
pole protein required for spindle maintenance and timely mitotic progression. J Cell Sci 125:5096-5109.

Boutin C, Labedan P, Dimidschstein J, Richard F, Cremer H, André P, Yang Y, Montcouquiol M, Goffinet AM, Tissir F (2014) A dual role for planar cell polarity genes in ciliated cells. Proc Natl Acad Sci U S A 111: E3129-E3138.

Breunig JJ, Sarkisian MR, Arellano JI, Morozov YM, Ayoub AE, Sojitra S, Wang B, Flavell RA, Rakic P, Town T (2008) Primary cilia regulate hippocampal neurogenesis by mediating sonic hedgehog signaling. Proc Natl Acad Sci U S A 105:13127-13132.

Chen JF, Zhang Y, Wilde J, Hansen KC, Lai F, Niswander L (2014) Microcephaly disease gene $\mathrm{Wdr} 62$ regulates mitotic progression of embryonic neural stem cells and brain size. Nat Commun 5:3885.

Cho JH, Chang CJ, Chen CY, Tang TK (2006) Depletion of CPAP by RNAi disrupts centrosome integrity and induces multipolar spindles. Biochem Biophys Res Commun 339:742-747.

Codega P, Silva-Vargas V, Paul A, Maldonado-Soto AR, Deleo AM, Pastrana E, Doetsch F (2014) Prospective identification and purification of quiescent adult neural stem cells from their in vivo niche. Neuron 82: 545-559.

Conduit PT, Wainman A, Novak Z, Weil TT, Raff JW (2015) Re-examining the role of Drosophila Sas-4 in centrosome assembly using two-colour3D-SIM FRAP. Elife 4: pii: e08483.

Doetsch F, Caillé I, Lim DA, García-Verdugo JM, Alvarez-Buylla A (1999) Subventricular zone astrocytes are neural stem cells in the adult mammalian brain. Cell 97:703-716.

Dzhindzhev NS, Yu QD, Weiskopf K, Tzolovsky G, Cunha-Ferreira I, Riparbelli M, Rodrigues-Martins A, Bettencourt-Dias M, Callaini G, Glover DM (2010) Asterless is a scaffold for the onset of centriole assembly. Nature 467:714-718.

Firat-Karalar EN, Stearns T (2014) The centriole duplication cycle. Philos Trans R Soc Lond B Biol Sci 369:20130460.

Fujimori A, Itoh K, Goto S, Hirakawa H, Wang B, Kokubo T, Kito S, Tsukamoto S, Fushiki S (2014) Disruption of aspm causes microcephaly with abnormal neuronal differentiation. Brain Dev 36:661-669.

Gabriel E, Wason A, Ramani A, Gooi LM, Keller P, Pozniakovsky A, Poser I, Noack F, Telugu NS, Calegari F, Šarić T, Hescheler J, Hyman AA, Gottardo M, Callaini G, Alkuraya FS, Gopalakrishnan J (2016) CPAP promotes timely cilium disassembly to maintain neural progenitor pool. EMBO J 35:803-819.

Gajera CR, Emich H, Lioubinski O, Christ A, Beckervordersandforth-Bonk R, Yoshikawa K, Bachmann S, Christensen EI, Götz M, Kempermann G, Peterson AS, Willnow TE, Hammes A (2010) LRP2 in ependymal cells regulates BMP signaling in the adult neurogenic niche. J Cell Sci 123: 1922-1930.

Garcez PP, Diaz-Alonso J, Crespo-Enriquez I, Castro D, Bell D, Guillemot F (2015) Cenpj/CPAP regulates progenitor divisions and neuronal migration in the cerebral cortex downstream of Ascl1. Nat Commun 6:6474.

García AD, Doan NB, Imura T, Bush TG, Sofroniew MV (2004) GFAPexpressing progenitors are the principal source of constitutive neurogenesis in adult mouse forebrain. Nat Neurosci 7:1233-1241.

Gönczy P (2012) Towards a molecular architecture of centriole assembly. Nat Rev Mol Cell Biol 13:425-435.

Gopalakrishnan J, Mennella V, Blachon S, Zhai B, Smith AH, Megraw TL, Nicastro D, Gygi SP, Agard DA, Avidor-Reiss T (2011) Sas-4 provides a scaffold for cytoplasmic complexes and tethers them in a centrosome. Nat Commun 2:359.

Guérout N, Li X, Barnabé-Heider F (2014) Cell fate control in the developing central nervous system. Exp Cell Res 321:77-83.

Gul A, Hassan MJ, Hussain S, Raza SI, Chishti MS, Ahmad W (2006) A novel deletion mutation in CENPJ gene in a pakistani family with autosomal recessive primary microcephaly. J Hum Genet 51:760-764.

Han YG, Spassky N, Romaguera-Ros M, García-Verdugo JM, Aguilar A, Schneider-Maunoury S, Alvarez-Buylla A (2008) Hedgehog signaling and primary cilia are required for the formation of adult neural stem cells. Nat Neurosci 11:277-284.

Hirono M (2014) Cartwheel assembly. Philos Trans R Soc Lond B Biol Sci 369:20130458.

Houlihan SL, Feng Y (2014) The scaffold protein Nde1 safeguards the brain genome during $\mathrm{S}$ phase of early neural progenitor differentiation. Elife 3:e03297.

Hu WF, Pomp O, Ben-Omran T, Kodani A, Henke K, Mochida GH, Yu TW,
Woodworth MB, Bonnard C, Raj GS, Tan TT, Hamamy H, Masri A, Shboul M, Al Saffar M, Partlow JN, Al-Dosari M, Alazami A, Alowain M, Alkuraya FS, et al. (2014) Katanin p80 regulates human cortical development by limiting centriole and cilia number. Neuron 84:1240-1257.

Hung LY, Chen HL, Chang CW, Li BR, Tang TK (2004) Identification of a novel microtubule-destabilizing motif in CPAP that binds to tubulin heterodimers and inhibits microtubule assembly. Mol Biol Cell 15:26972706.

Insolera R, Bazzi H, Shao W, Anderson KV, Shi SH (2014) Cortical neurogenesis in the absence of centrioles. Nat Neurosci 17:1528-1535.

Kim S, Tsiokas L (2011) Cilia and cell cycle re-entry: more than a coincidence. Cell Cycle 10:2683-2690.

Kim S, Zaghloul NA, Bubenshchikova E, Oh EC, Rankin S, Katsanis N, Obara T, Tsiokas L (2011) Nde1-mediated inhibition of ciliogenesis affects cell cycle re-entry. Nat Cell Biol 13:351-360.

Kirkham M, Müller-Reichert T, Oegema K, Grill S, Hyman AA (2003) SAS-4 is a C-elegans centriolar protein that controls centrosome size. Cell 112:575-587.

Kitagawa D, Kohlmaier G, Keller D, Strnad P, Balestra FR, Flückiger I, Gönczy $P$ (2011) Spindle positioning in human cells relies on proper centriole formation and on the microcephaly proteins CPAP and STIL. J Cell Sci 124:3884-3893

Kobayashi T, Dynlacht BD (2011) Regulating the transition from centriole to basal body. J Cell Biol 193:435-444.

Kohlmaier G, Loncarek J, Meng X, McEwen BF, Mogensen MM, Spektor A, Dynlacht BD, Khodjakov A, Gönczy P (2009) Overly long centrioles and defective cell division upon excess of the SAS-4-related protein CPAP. Curr Biol 19:1012-1018.

Kuo CT, Mirzadeh Z, Soriano-Navarro M, Rasin M, Wang D, Shen J, Sestan N, García-Verdugo J, Alvarez-Buylla A, Jan LY, Jan YN (2006) Postnatal deletion of Numb/Numblike reveals repair and remodeling capacity in the subventricular neurogenic niche. Cell 127:1253-1264.

Leal GF, Roberts E, Silva EO, Costa SM, Hampshire DJ, Woods CG (2003) A novel locus for autosomal recessive primary microcephaly (MCPH6) maps to 13q12.2. J Med Genet 40:540-542.

Lee KH, Johmura Y, Yu LR, Park JE, Gao Y, Bang JK, Zhou M, Veenstra TD, Yeon Kim B, Lee KS (2012) Identification of a novel Wnt5aCK1varepsilon-Dvl2-Plk1-mediated primary cilia disassembly pathway. EMBO J 31:3104-3117.

Lehtinen MK, Zappaterra MW, Chen X, Yang YJ, Hill AD, Lun M, Maynard T, Gonzalez D, Kim S, Ye P, D’Ercole AJ, Wong ET, LaMantia AS, Walsh CA (2011) The cerebrospinal fluid provides a proliferative niche for neural progenitor cells. Neuron 69:893-905.

Li A, Saito M, Chuang JZ, Tseng YY, Dedesma C, Tomizawa K, Kaitsuka T, Sung CH (2011) Ciliary transition zone activation of phosphorylated tctex-1 controls ciliary resorption, S-phase entry and fate of neural progenitors. Nat Cell Biol 13:402-411.

Liang Y, Meng D, Zhu B, Pan J (2016) Mechanism of ciliary disassembly. Cell Mol Life Sci 73:1787-1802.

Lienkamp S, Ganner A, Walz G (2012) Inversin, Wnt signaling and primary cilia. Differentiation 83:S49-S55.

Lim DA, Tramontin AD, Trevejo JM, Herrera DG, García-Verdugo JM, Alvarez-Buylla A (2000) Noggin antagonizes BMP signaling to create a niche for adult neurogenesis. Neuron 28:713-726.

Lizarraga SB, Margossian SP, Harris MH, Campagna DR, Han AP, Blevins S, Mudbhary R, Barker JE, Walsh CA, Fleming MD (2010) Cdk5rap2 regulates centrosome function and chromosome segregation in neuronal progenitors. Development 137:1907-1917.

Marthiens V, Rujano MA, Pennetier C, Tessier S, Paul-Gilloteaux P, Basto R (2013) Centrosome amplification causes microcephaly. Nat Cell Biol 15: 731-740.

Maskey D, Marlin MC, Kim S, Kim S, Ong EC, Li G, Tsiokas L (2015) Cell cycle-dependent ubiquitylation and destruction of NDE1 by CDK5FBW7 regulates ciliary length. EMBO J 34:2424-2440.

McIntyre RE, Lakshminarasimhan CP, Ismail O, Carragher DM, SanchezAndrade G, Forment JV, Fu B, Del Castillo Velasco-Herrera M, Edwards A, van der Weyden L, Yang F, Sanger Mouse Genetics Project, RamirezSolis R, Estabel J, Gallagher FA, Logan DW, Arends MJ, Tsang SH, Mahajan VB, Scudamore CL, et al. (2012) Disruption of mouse Cenpj, a regulator of centriole biogenesis, phenocopies Seckel syndrome. PLoS Genet 8:e1003022.

Mirzadeh Z, Merkle FT, Soriano-Navarro M, García-Verdugo JM, Alvarez- 
Buylla A (2008) Neural stem cells confer unique pinwheel architecture to the ventricular surface in neurogenic regions of the adult brain. Cell Stem Cell 3:265-278.

Mirzadeh Z, Han YG, Soriano-Navarro M, García-Verdugo JM, AlvarezBuylla A (2010) Cilia organize ependymal planar polarity. J Neurosci 30:2600-2610.

Miyamoto T, Hosoba K, Ochiai H, Royba E, Izumi H, Sakuma T, Yamamoto T, Dynlacht BD, Matsuura S (2015) The microtubule-depolymerizing activity of a mitotic kinesin protein KIF2A drives primary cilia disassembly coupled with cell proliferation. Cell Rep 10:664-673.

Mohan S, Timbers TA, Kennedy J, Blacque OE, Leroux MR (2013) Striated rootlet and nonfilamentous forms of rootletin maintain ciliary function. Curr Biol 23:2016-2022.

Nigg EA, Stearns T (2011) The centrosome cycle: centriole biogenesis, duplication and inherent asymmetries. Nat Cell Biol 13:1154-1160.

O'Connor AK, Malarkey EB, Berbari NF, Croyle MJ, Haycraft CJ, Bell PD, Hohenstein P, Kesterson RA, Yoder BK (2013) An inducible CiliaGFP mouse model for in vivo visualization and analysis of cilia in live tissue. Cilia 2:8.

Paez-Gonzalez P, Abdi K, Luciano D, Liu Y, Soriano-Navarro M, Rawlins E, Bennett V, García-Verdugo JM, Kuo CT (2011) Ank3-dependent SVZ niche assembly is required for the continued production of new neurons. Neuron 71:61-75.

Paridaen JT, Wilsch-Bräuninger M, Huttner WB (2013) Asymmetric inheritance of centrosome-associated primary cilium membrane directs ciliogenesis after cell division. Cell 155:333-344.

Pawlisz AS, Mutch C, Wynshaw-Boris A, Chenn A, Walsh CA, Feng Y (2008) Lis1-Nde1-dependent neuronal fate control determines cerebral cortical size and lamination. Hum Mol Genet 17:2441-2455.

Pugacheva EN, Jablonski SA, Hartman TR, Henske EP, Golemis EA (2007) HEF1-dependent aurora a activation induces disassembly of the primary cilium. Cell 129:1351-1363.

Qin H, Wang Z, Diener D, Rosenbaum J (2007) Intraflagellar transport protein 27 is a small $G$ protein involved in cell-cycle control. Curr Biol 17:193-202.

Ramírez-Castillejo C, Sánchez-Sánchez F, Andreu-Agulló C, Ferrón SR, Aroca-Aguilar JD, Sánchez P, Mira H, Escribano J, Fariñas I (2006) Pigment epithelium-derived factor is a niche signal for neural stem cell renewal. Nat Neurosci 9:331-339.

Robert A, Margall-Ducos G, Guidotti JE, Brégerie O, Celati C, Bréchot C, Desdouets C (2007) The intraflagellar transport component IFT88/polaris is a centrosomal protein regulating G1-S transition in non-ciliated cells. J Cell Sci 120:628-637.

Sánchez I, Dynlacht BD (2016) Cilium assembly and disassembly. Nat Cell Biol 18:711-717.

Schmidt TI, Kleylein-Sohn J, Westendorf J, Le Clech M, Lavoie SB, Stierhof YD, Nigg EA (2009) Control of centriole length by CPAP and CP110. Curr Biol 19:1005-1011.

Seeger-Nukpezah T, Liebau MC, Hopker K, Lamkemeyer T, Benzing T, Golemis EA, Schermer B (2012) The Centrosomal Kinase Plk1 Localizes to the Transition Zone of Primary Cilia and Induces Phosphorylation of Nephrocystin-1. PLoS One 7: e38838.
Silver DL, Watkins-Chow DE, Schreck KC, Pierfelice TJ, Larson DM, Burnetti AJ, Liaw HJ, Myung K, Walsh CA, Gaiano N, Pavan WJ (2010) The exon junction complex component magoh controls brain size by regulating neural stem cell division. Nat Neurosci 13:551-558.

Spassky N, Merkle FT, Flames N, Tramontin AD, García-Verdugo JM, Alvarez-Buylla A (2005) Adult ependymal cells are postmitotic and are derived from radial glial cells during embryogenesis. J Neurosci 25:10-18.

Tang CJ, Fu RH, Wu KS, Hsu WB, Tang TK (2009) CPAP is a cell-cycle regulated protein that controls centriole length. Nat Cell Biol 11:825-831.

Trinczek B, Brajenovic M, Ebneth A, Drewes G (2004) MARK4 is a novel microtubule-associated proteins/microtubule affinity-regulating kinase that binds to the cellular microtubule network and to centrosomes. J Biol Chem 279:5915-5923.

Walczak CE, Gayek S, Ohi R (2013) Microtubule-depolymerizing kinesins. Annu Rev Cell Dev Biol 29:417-441.

Wallingford JB (2010) Planar cell polarity signaling, cilia and polarized ciliary beating. Curr Opin Cell Biol 22:597-604.

Wallingford JB, Mitchell B (2011) Strange as it may seem: the many links between wnt signaling, planar cell polarity, and cilia. Gene Dev 25: 201-213.

Wang G, Chen Q, Zhang X, Zhang B, Zhuo X, Liu J, Jiang Q, Zhang C (2013) PCM1 recruits Plk1 to the pericentriolar matrix to promote primary cilia disassembly before mitotic entry. J Cell Sci 126:1355-1365.

Wang W, Wu T, Kirschner MW (2014) The master cell cycle regulator APCCdc20 regulates ciliary length and disassembly of the primary cilium. Elife 3:e03083

Wang X, Tsai JW, Imai JH, Lian WN, Vallee RB, Shi SH (2009) Asymmetric centrosome inheritance maintains neural progenitors in the neocortex. Nature 461:947-955.

Willaredt MA, Hasenpusch-Theil K, Gardner HA, Kitanovic I, HirschfeldWarneken VC, Gojak CP, Gorgas K, Bradford CL, Spatz J, Wölfl S, Theil T, Tucker KL (2008) A crucial role for primary cilia in cortical morphogenesis. J Neurosci 28:12887-12900.

Williams SE, García I, Crowther AJ, Li S, Stewart A, Liu H, Lough KJ, O’Neill S, Veleta K, Oyarzabal EA, Merrill JR, Shih YY, Gershon TR (2015) Aspm sustains postnatal cerebellar neurogenesis and medulloblastoma growth in mice. Development 142:3921-3932.

Wilson SL, Wilson JP, Wang C, Wang B, McConnell SK (2012) Primary cilia and Gli3 activity regulate cerebral cortical size. Dev Neurobiol 72: $1196-1212$.

Wu KS, Tang TK (2012) CPAP is required for cilia formation in neuronal cells. Biol Open 1:559-565.

Yang J, Gao J, Adamian M, Wen XH, Pawlyk B, Zhang L, Sanderson MJ, Zuo J, Makino CL, Li T (2005) The ciliary rootlet maintains long-term stability of sensory cilia. Mol Cell Biol 25:4129-4137.

Zheng X, Gooi LM, Wason A, Gabriel E, Mehrjardi NZ, Yang Q, Zhang X, Debec A, Basiri ML, Avidor-Reiss T, Pozniakovsky A, Poser I, Saric T, Hyman AA, Li H, Gopalakrishnan J (2014) Conserved TCP domain of sas-4/CPAP is essential for pericentriolar material tethering during centrosome biogenesis. Proc Natl Acad Sci U S A 111:E354-E363. 